\title{
Catalytic Unmixed Combustion of Coal with Zero Pollution
}

\author{
Final Technical Report \\ Reporting Period: \\ October 1, 2003 - September 30, 2005 \\ George Rizeq, Parag Kulkarni, Raul Subia, Wei Wei \\ (GE Global Research)
}

\section{December 2005}

DOE Award No. DE-FC26-03NT41842

GE Global Research

(GEGR)

18A Mason

Irvine, CA 92618 


\section{DISCLAIMER}

"This report was prepared as an account of work sponsored by an agency of the United States Government. Neither the United States Government nor any agency thereof, nor any of their employees, makes any warranty, express or implied, or assumes any legal liability or responsibility for the accuracy, completeness, or usefulness of any information, apparatus, product, or process disclosed, or represents that its use would not infringe privately owned rights. Reference herein to any specific commercial product, process, or service by trade name, trademark, manufacturer, or otherwise does not necessarily constitute or imply its endorsement, recommendation, or favoring by the United States Government or any agency thereof. The views and opinions of authors expressed herein do not necessarily state or reflect those of the United States Government or any agency thereof." 


\section{ABSTRACT}

GE Global Research is developing an innovative energy-based technology for coal combustion with high efficiency and near-zero pollution. This Unmixed Combustion of coal (UMC-Coal) technology simultaneously converts coal, steam and air into two separate streams of high pressure $\mathrm{CO}_{2}$-rich gas for sequestration, and high-temperature, high-pressure vitiated air for producing electricity in gas turbine expanders. The UMC process utilizes an oxygen transfer material (OTM) and eliminates the need for an air separation unit (ASU) and a $\mathrm{CO}_{2}$ separation unit as compared to conventional gasification based processes. This is the final report for the two-year DOE-funded program (DE-FC26-03NT41842) on this technology that ended in September 30, 2005. The UMC technology development program encompassed lab- and pilotscale studies to demonstrate the UMC concept. The chemical feasibility of the individual UMC steps was established via lab-scale testing. A pilot plant, designed in a related DOE funded program (DE-FC26-00FT40974), was reconstructed and operated to demonstrate the chemistry of UMC process in a pilot-scale system. The risks associated with this promising technology including cost, lifetime and durability OTM and the impact of contaminants on turbine performance are currently being addressed in detail in a related ongoing DOE funded program (DE-FC26-00FT40974, Phase II). Results obtained to date suggest that this technology has the potential to economically meet future efficiency and environmental performance goals. 


\section{TABLE OF CONTENT}

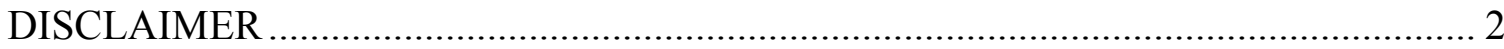

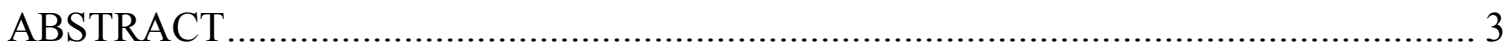

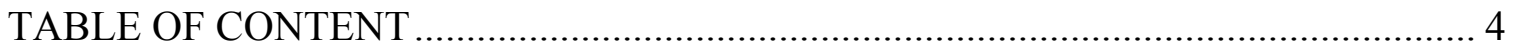

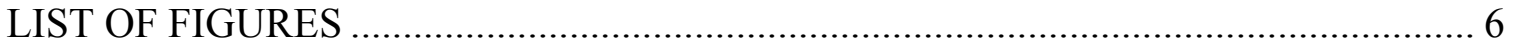

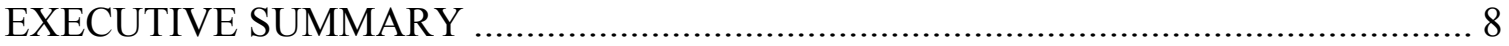

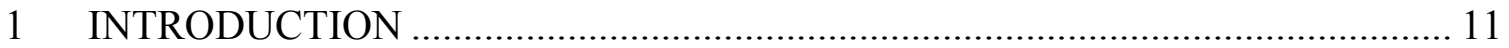

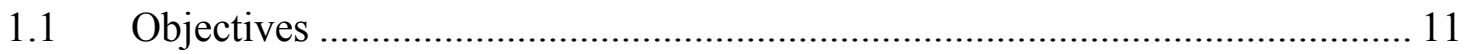

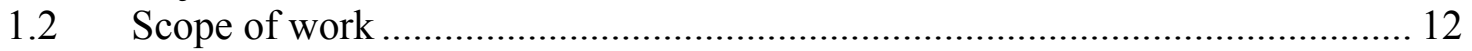

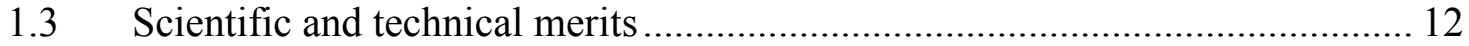

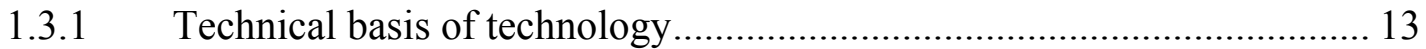

1.3.2 Practical applications for unmixed combustion of coal.......................... 14

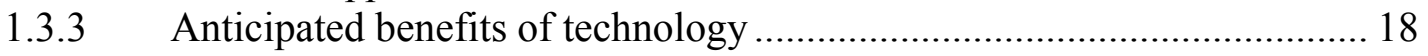

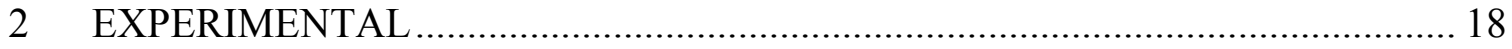

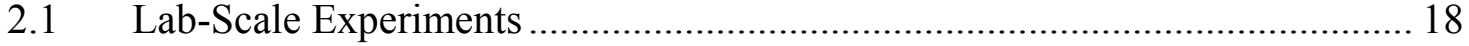

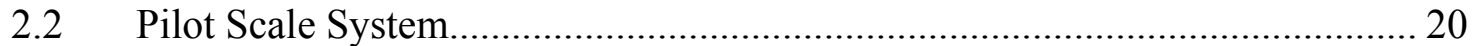

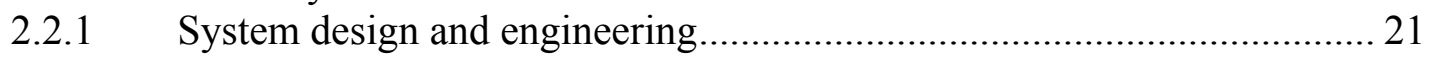

(1) Dense Phase Solid Circulation Testing............................................. 21

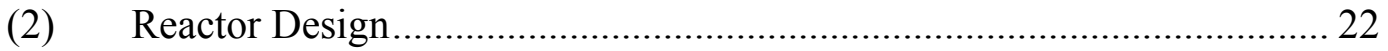

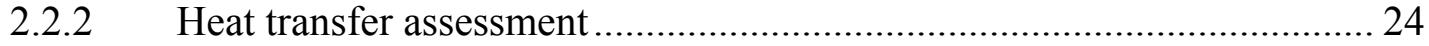

2.2.3 Reducing heat loss through additional insulation ................................... 25

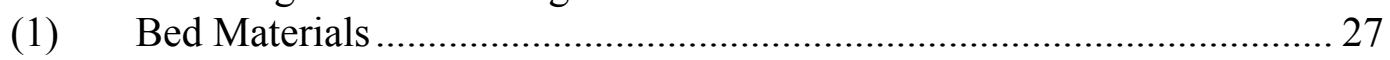

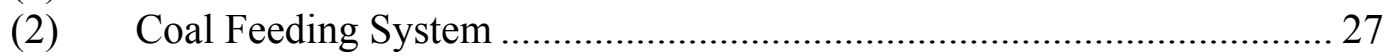

2.2.4 System fabrication, assembly and shakedown..................................... 29

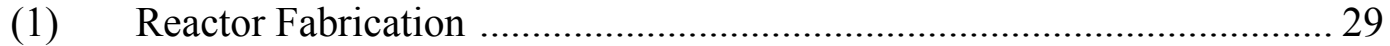

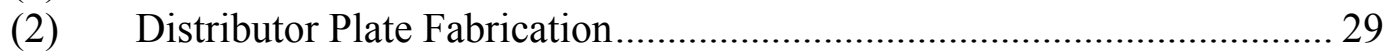

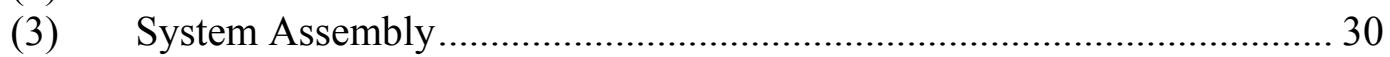

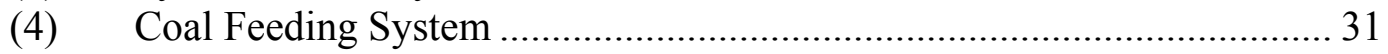

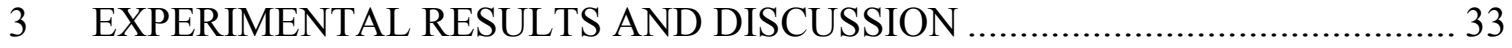

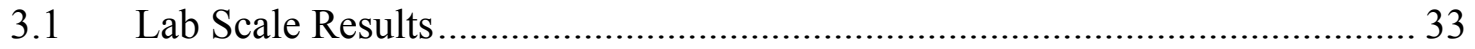

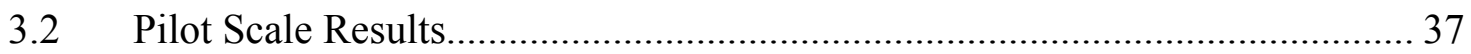

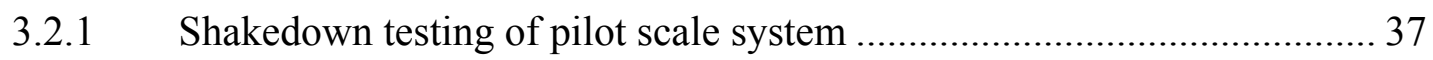

3.2.2 Operation of the pilot plant ............................................................. 38

3.2.3 Challenges faced during operation \& recommendations ......................... 43

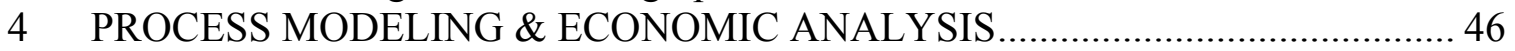

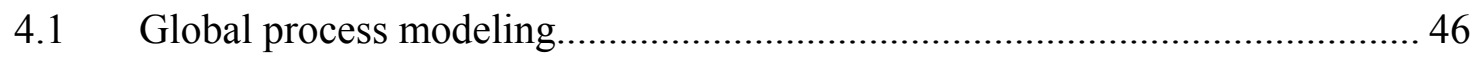

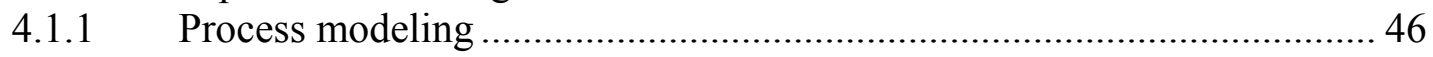

(1) Selection of Process Modeling Tool .................................................... 46

(2) ASPEN Plus Based Process Modeling …........................................ 47

(3) Description of UMC of Coal PFD ................................................... 48 
(4) Major Process Analysis Assumptions................................................. 48

4.1.2 UMC-Coal efficiency estimates and comparison with IGCC.................. 50

4.2 Process Modeling to Identify Initial Experimental Conditions ........................ 52

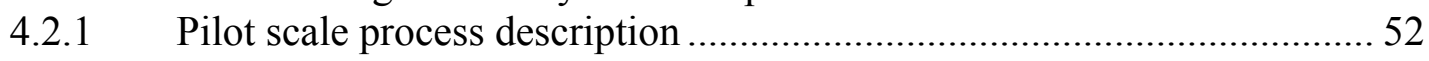

4.2.2 Major process analysis assumptions ................................................. 53

4.2.3 UMC pilot scale system modeling results .......................................... 53

4.3 Process Design \& Economics of Commercial Scale UMC-2Reactor System.. 56

4.3.1 Commercial scale UMC system modeling ........................................... 56

4.3.2 Fluidization calculations and reactor vessel sizing methodology ............. 56

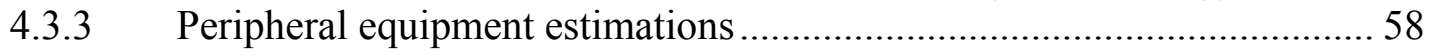

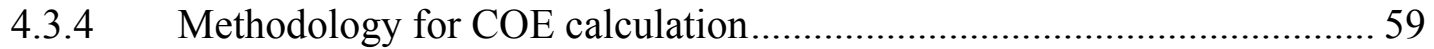

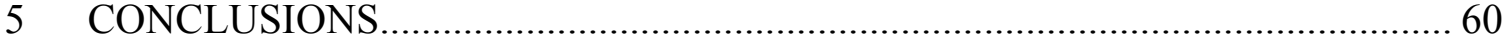

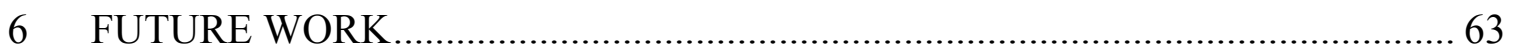




\section{LIST OF FIGURES}

Figure 1-1 Conceptual design for solid fuels combustion using UMC technology......... 13

Figure 1-2 UMC based combined cycle power generation system .............................. 15

Figure 1-3 Comparison of combustion approaches using oxygen transfer catalysts........ 16

Figure 2-1 Schematic diagrams of PARR high-pressure reactor assembly.................... 18

Figure 2-2 Complete high-pressure reactor, furnace and controller assembly ............... 19

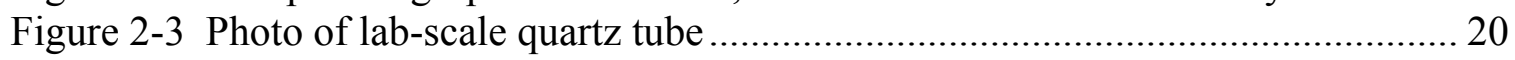

Figure 2-4 Atmospheric metal reduction tests in lab-scale quartz tube reactor............... 20

Figure 2-5 Experimental setup for PYROX process evaluation................................. 21

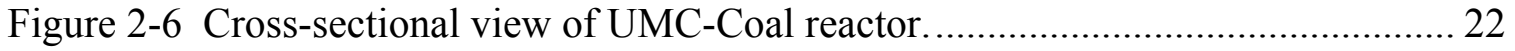

Figure 2-7 Solids transfer duct drawing.................................................................. 23

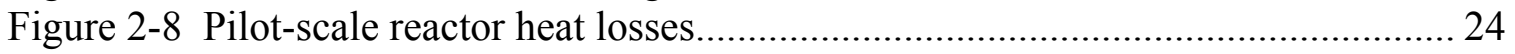

Figure 2-9 Cross-sectional view of baseline pilot-scale reactor. ..................................... 26

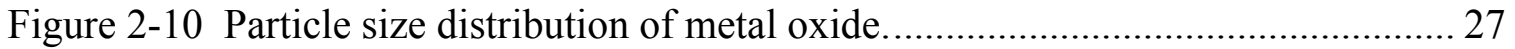

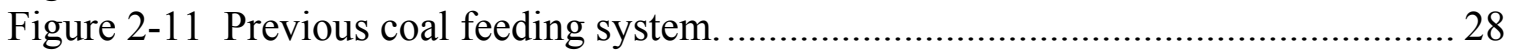

Figure 2-12 Revised coal feeding system with upgrades shown in green..................... 29

Figure 2-13 Photo of Reactor 1 refractory layers. ..................................................... 29

Figure 2-14 Photo of facility with assembled core components ................................... 30

Figure 2-15 Photo of reactors shown assembled on support frame--top view ................ 30

Figure 2-16 Photo of reactors shown assembled on support frame-bottom view ......... 31

Figure 2-17 Coal slurry calibration curve from upgraded coal feeding system. ............ 32

Figure 3-1 Coal gasification product gas composition at different temperatures............ 33

Figure 3-2 Product gas composition Vs steam flow rates.......................................... 34

Figure 3-3 Product gas composition Vs OTM/coal ratios. ............................................. 35

Figure 3-4 Test results - outlet methane Vs OTM loadings......................................... 35

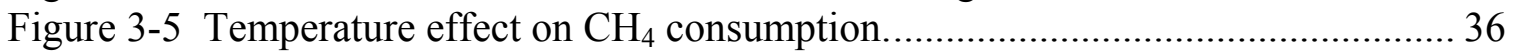

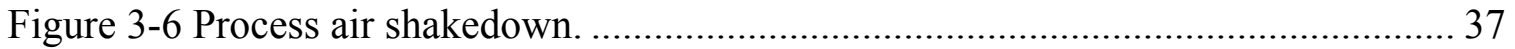

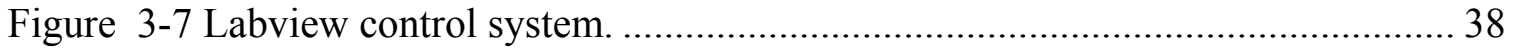

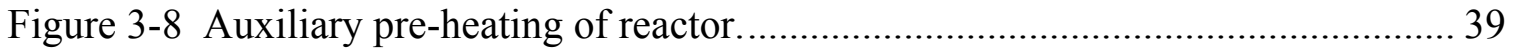

Figure 3-9 Typical temperature profile of R1 cycling in gasification and oxidation

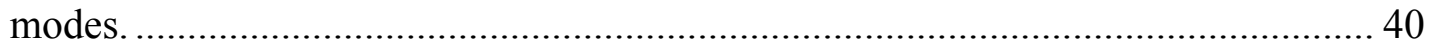

Figure 3-10 Concentration and temperature profile for Reactor 1 simulated operation.. 42

Figure 3-11 Concentration and temperature profile for Reactor 2 simulated operation... 43

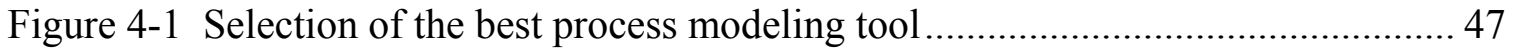

Figure 4-2 Simplified process diagram of UMC-Coal to electricity ............................. 49

Figure 4-3 Process flow diagram for the 3-pressure reheat steam cycle ........................ 50

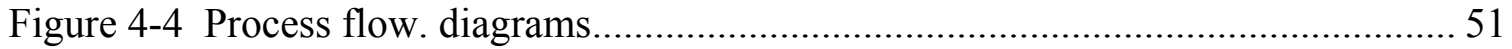

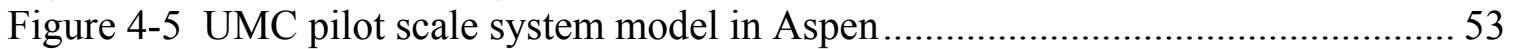

Figure 4-6 UMC pilot scale system operation conditions. ......................................... 55

Figure 4-7 Fluidization calculations and reactor sizing.......................................... 57

Figure 4-8 Reactor length for different particle sizes. ............................................... 58 
Figure 4-9 Refractory and shell thickness estimation............................................ 58 


\section{EXECUTIVE SUMMARY}

GE's Unmixed Combustion (UMC) of coal is an innovative technology for coal-based energy plants. This final report summarizes program accomplishments for the DOEfunded $R \& D$ program investigating the UMC technology. The program included lab- and pilot-scale experimental studies, as well as process modeling and a preliminary economic assessment. The experimental investigations were designed to provide information on the key reactions and cycles in a controlled environment. Process and kinetic modeling efforts were used to relate experimental data to different operating conditions, scales, and energy plant integration scenarios, as well as assessing the costs of different options. The results obtained to date from this program have confirmed the fundamentals of the technology and underscore the need for further development.

The Unmixed Combustion of coal (UMC-Coal) technology simultaneously converts coal, steam and air into two separate streams of high pressure $\mathrm{CO}_{2}$-rich gas for sequestration, and high-temperature, high-pressure vitiated air for producing electricity in gas turbine expanders. The UMC process utilizes an oxygen transfer material (OTM) and eliminates

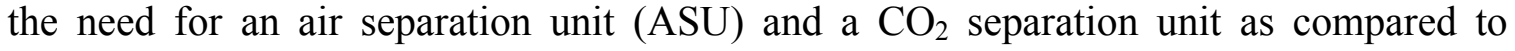
conventional gasification based processes producing electricity with $\mathrm{CO}_{2}$ separation.

The current program to investigate the novel UMC-coal technology has successfully validated the chemistry aspects of the technology in a pilot-scale system. The program objectives were met through lab-scale experimentation, successful reconstruction of a pilot plant, and pilot-scale testing. Although only limited pilot plant testing data was collected because of delays associated with an unplanned move of facilities from Irvine, CA to Santa Ana, CA, the team was able to get important technical data to validate the chemistry associated with the technology. The pilot plant, designed in a previous DOE funded program (DE-FC26-00FT40974), was reconstructed and operated for extended period for the first time. Limitations of the current design and several upgrades required in the design were identified. Global process modeling of the technology was completed and a methodology to compare the cost of the UMC technology with the conventional gasification technology was developed. Although additional work is needed at the pilot scale to further characterize performance and retire risks such as cost, sorbent lifetime and impact of pollutants, the results obtained to date suggest that the UMC technology has the capability to meet the efficiency, environmental and economic goals of both the DOE and industrial customers. The risks associated with the UMC technology are currently being addressed in another DOE funded project ending in September 2007 (DEFC26-00FT40974. Phase II) and therefore GE would be in a better position to make recommendation about the UMC-Coal technology in 2007.

In the current program, the subcontractor, Southern Illinois University at Carbondale (SIU), performed lab-scale tests by designing an experimental fixed bed system capable 
of operating at high pressure and temperature (300 psi, 800C). Parametric experiments on steam gasification of coal in the presence of OTM were carried out. The operating parameters such as the temperature, steam to carbon ratio and the OTM/coal ratio were validated using this study. To get more quantitative and relevant technical information for the development of UMC technology, a more robust experimental system capable of handling temperatures of up to approximately $1200^{\circ} \mathrm{C}$ under high pressure is required. Also, kinetics of various reactions involved in the UMC process needs to be established using the lab-scale experiments.

A pilot plant experimental facility designed in a previous related DOE funded program (\#DE-FC26-00FT40974) was redesigned for the UMC-coal process. Several modifications were performed in the existing design in order to make the facility more robust and reliable. The refractory thickness in the reactors was increased to reduce the heat loss; the coal slurry system was modified to minimize plugging. Various designs for solid circulation were considered and validated using a cold flow system and the most reliable design was implemented at the pilot scale.

The pilot-scale facility was operated and the chemistry associated with the UMC-coal process was validated by single reactor cyclic operation. During the gasification/combustion stage $\mathrm{CO}_{2}$ was the major detectable product. During the oxidation stage oxygen in the air was consumed by the OTM and high temperature vitiated air was produced. Several limitations of the current pilot-plant design were identified during the operation especially related to auxiliary heating and coal slurry feeding. Agglomeration of the bed material, most likely due to melting of alkali metals in the ash, was also observed during the cyclic experiments. Only limited pilot-plant operation was possible because of these limitations. Currently the design is being upgraded under another DOE funded program on UMC-related technology (DE-FC2600FT40974. Phase II). The major upgrades needed mainly include a robust auxiliary heating system to maintain required operating temperatures and continuous removal of ash from the OTM material.

A methodology was developed to perform apples-to-apples economic comparison of the UMC-coal process with conventional gasification technologies at a commercial scale. Process models to get the overall material and energy balance were developed using AspenPlus and GateCycle software. Fluidization models were developed to identify the reactor dimensions and number of trains required to generate the required amount of electricity. The flow-rates and reactor sizes were sent to Worley Parsons for capital cost (CAPEX) estimates. Based on the CAPEX estimates the cost of electricity (COE) was calculated using a model developed on the basis of DOE's H2A model. GE is currently reviewing the economics internally.

Future work planned for the UMC technology is aimed at reducing the technical and economic risks associated with a commercial full-scale UMC-based energy plant. Although developments efforts have thus far focused on the fundamental reactions and 
processes of the UMC, continuing development will also consider and assess issues such as combined cycle plant integration, environmental impact, and long-term control and operability; issues that directly impact the economic and commercialization potential of the UMC-Coal process. The process design will be updated and serve as the basis for an assessment of the economic viability of a full-scale UMC-based system. The risks associated with the UMC-coal technology are common to the current DOE-funded UMC3Reactor technology (DE-FC26-00FT40974. Phase II) capable of producing three separate stream of hydrogen, sequestration ready $\mathrm{CO}_{2}$ and high temperature, high pressure vitiated air. The team is currently working on investigating and retiring these risks. The future work identified for the UMC-Coal technology is synergistic with what will be addressed in the UMC-3Reactor program in 2006-07. 


\section{INTRODUCTION}

Projections of increased demands for energy worldwide, coupled with increasing environmental concerns have given rise to the need for new and innovative technologies for coal-based energy plants. Incremental improvements in existing plants will likely fall short of meeting future capacity and environmental needs economically. The objective of this research and development program was to investigate GE's novel Unmixed combustion of coal (UMC-Coal) technology and assess the technical viability of the technology at both bench and pilot scales, as well as through engineering and modeling efforts.

The UMC technology is a new, energy-efficient, and near-zero pollution concept for converting coal into two separate streams of high pressure $\mathrm{CO}_{2}$ for sequestration, and high-temperature, high-pressure vitiated air to produce electricity in gas turbine expanders. The UMC process utilizes an oxygen transfer material (OTM) and eliminates the need for the costly and energy intensive air separation unit (ASU) and the $\mathrm{CO}_{2}$ separation unit as compared to the conventional gasification based processes. When commercialized, the UMC technology may become one of the cornerstone technologies to meet the DOE's future energy plant objectives of efficiently and economically producing energy with $\mathrm{CO}_{2}$ sequestration from coal with utilization of opportunity feedstocks.

GE Global Research is the primary contractor for the UMC program under a contract from U.S. DOE NETL (Contract No. DE-FC26-03NT41842). Other project team members include Southern Illinois University at Carbondale (SIU). This project integrated lab- and pilot-scale studies to demonstrate the UMC technology. Engineering studies and analytical modeling were also performed in conjunction with the experimental program to provide insight into process behavior as well as aid design efforts. Completion of this stage of the research program has provided evidence of the viability of the main principles of the UMC technology and underscores the need for continued evaluation.

\subsection{Objectives}

The overall objective of this research and development program is to investigate the GE GRC technology for producing electrical power through catalytic unmixed combustion of coal (UMC-Coal) in a pilot-scale facility.

Specific objectives of the program are to (1) demonstrate at pilot-scale the process of converting solid fuels into separate streams of sequestration-ready $\mathrm{CO}_{2}$ and a hightemperature, high-pressure vitiated air stream capable of producing electricity in a gas 
turbine; (2) optimize catalyst performance and determine operating conditions that maximize the separation of $\mathrm{CO}_{2}$ and pollutants from the vent gas, while simultaneously maximizing coal conversion efficiency; (3) optimize the overall process configuration for an integrated combined-cycle power generation system and determine the process efficiency; and (4) estimate the preliminary economics of the process as applied to a combined-cycle power generation system.

\subsection{Scope of work}

The scope of the work included lab-scale and pilot-scale experimentation, as well as development of process and economic models for an integrated full-scale system. An existing lab-scale system was used to study fundamental process reactions to identify kinetic parameters and operational characteristics. This data was used to develop preliminary design models and operating limits for the pilot-scale test stand. An existing, pilot-scale experimental system was modified to meet the specified design requirements. This test stand was operated to provide experimental pilot-scale validation of the UMCCoal process chemistry. Modeling of full-scale facility involved systems integration with a combined-cycle power plant and work cycle efficiency calculations, as well as preliminary economic and market assessments to pave the way for process commercialization.

\subsection{Scientific and technical merits}

An inherent consequence of the UMC-Coal technology is that $\mathrm{NO}_{\mathrm{x}}$ formation due to nitrogen from air is avoided due to the unique approach of utilizing OTM in the unmixed combustion process. Moreover, this approach inherently separates the majority of $\mathrm{CO}_{2}$ from the bulk of the combustion products and has the potential to remove acid gases (such as $\mathrm{SO}_{2}$ ) and mineral matter with the $\mathrm{CO}_{2}$. This reduces the volume of gas that must be cleaned by about a factor of ten and should substantially reduce pollution control costs. The entire process is conducted at elevated pressure, which permits the heat generated by the OTM to be used in a combined cycle for production of electrical power, and reduces the cost of subsequent $\mathrm{CO}_{2}$ treatment prior to sequestration.

The underlying technology, referred to as Unmixed Combustion (UMC), is an advanced GE proprietary technology [U.S. Patents \#5,339,754 (1994); \#5,509,362 (1996); $\# 5,827,496$ (1998)]. Several UMC-based concepts to generate $\mathrm{H}_{2}$ (from coal, high-sulfur diesel, and natural gas) for fuel cell applications have been demonstrated successfully. The engineering requirements of the current process to generate electricity from coal (UMC of coal) are consistent with those of existing fluidized bed gasification/combustion technologies except that oxygen from OTM is used as oxidizer. In this approach, air is not directly mixed with fuel, allowing a metal oxide regenerator to replace the oxygen plant found in conventional gasification systems. This method has the potential to reduce capital and operating costs and eliminate energy losses associated with an oxygen plant, leading to improved efficiency. 


\subsubsection{Technical basis of technology}

Figure 1-1 shows an illustration of the UMC of coal concept in a circulating fluidized bed. This figure also shows a simplified example of how electricity can be generated from this technology by addition of auxiliary equipment such as gas turbines, compressors, heat exchangers, condensers, etc. Coal and steam are fed to the fluidized bed Reactor and air is fed to the Regenerator. A solid-state oxygen transfer material (OTM) is circulated between the Reactor and Regenerator to transfer oxygen. The connections between the Reactor and Regenerator are steam-purged to prevent crossover of gases.

The Reactor is primarily fluidized by steam. Coal is introduced at about mid point of the fluidized bed through an air lock. The steam gasifies the coal to produce syngas (a mixture of $\mathrm{CO}, \mathrm{H}_{2}, \mathrm{CO}_{2}$, small amount of hydrocarbons, and $\mathrm{H}_{2} \mathrm{O}$ ) at temperatures of

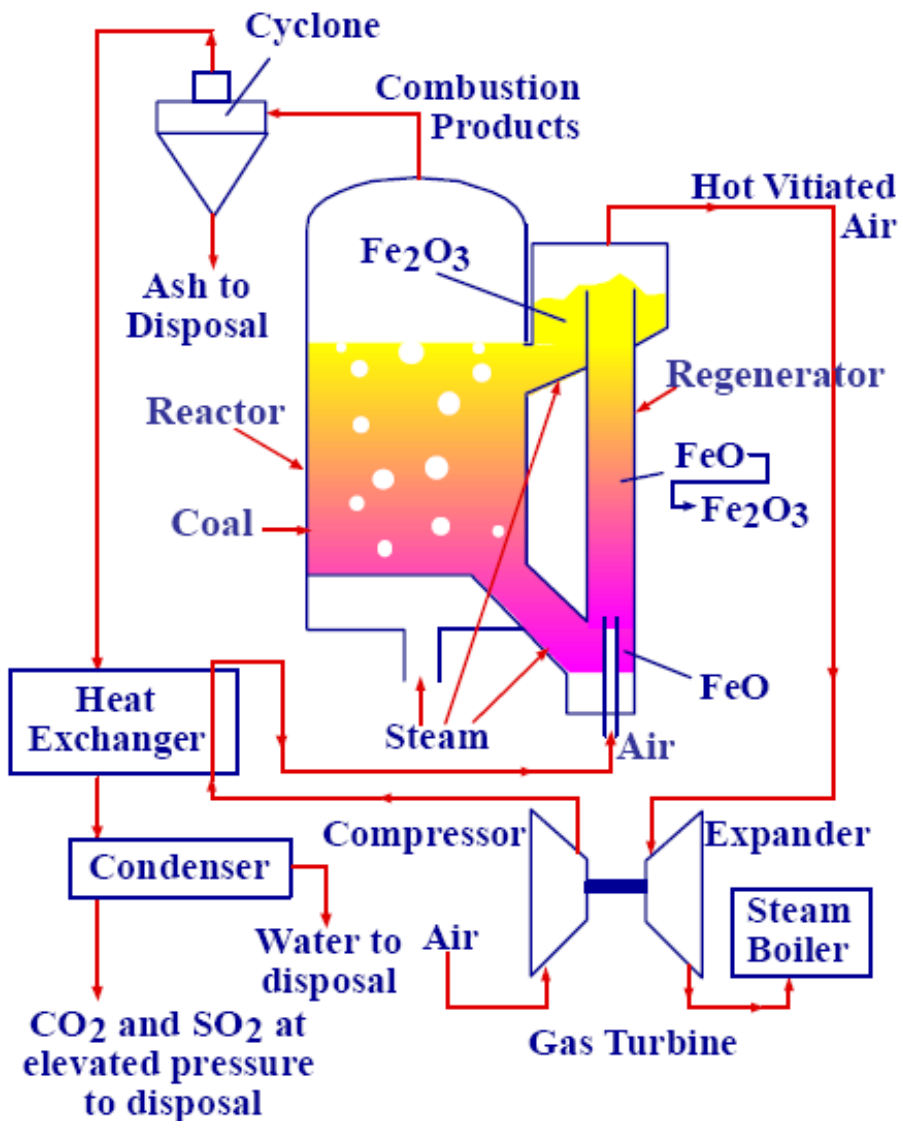

Figure 1-1 Conceptual design for solid fuels combustion using UMC technology. 
about $700-900^{\circ} \mathrm{C}\left(1292-1652^{\circ} \mathrm{F}\right)$. The OTM mixture is sub-stoichiometric with respect to coal so that only a portion of the OTM is reduced, but all of the coal gasification products (including tar) are oxidized in the Reactor. The three principal simplified reactions during this step are:

(1) $\mathrm{CH}_{0.8}$ (coal) $+\mathrm{H}_{2} \mathrm{O}=\mathrm{CO}+1.4 \mathrm{H}_{2}$

(2) $\mathrm{CO}+$ OTM-oxidized $=\mathrm{CO}_{2}+$ OTM-reduced

(3) $\mathrm{H}_{2}+$ OTM-oxidized $=\mathrm{H}_{2} \mathrm{O}+$ OTM-reduced

The above reactions can be represented by the following global reaction:

$\mathrm{CH}_{0.8}$ (coal) + OTM-oxidized $=\mathrm{CO}_{2}+0.4 \mathrm{H}_{2} \mathrm{O}+$ OTM-reduced (Mildly Endothermic)

Coal gasification products formed from fuel sulfur and fuel nitrogen (mainly $\mathrm{H}_{2} \mathrm{~S}$ and $\mathrm{NH}_{3}$ ) are oxidized by OTM to form $\mathrm{SO}_{2}$ and $\mathrm{NO}$. Previous GE GRC laboratory studies demonstrated that char oxidation by OTM in the presence of steam is catalyzed by $\mathrm{SO}_{2}$ via the following proposed mechanism involving radical SO:

$\mathrm{C}($ char $)+\mathrm{SO}_{2}=\mathrm{CO}+\mathrm{SO}$ and $\mathrm{SO}+\mathrm{OTM}$-oxidized $=\mathrm{SO}_{2}+\mathrm{OTM}$-reduced

At the exit of the Reactor, the carbon dioxide and all toxic pollutants $\left(\mathrm{SO}_{2}, \mathrm{NO}_{\mathrm{x}}\right.$ and $\left.\mathrm{Hg}\right)$ are isolated into a relatively low-volume product gas stream (no dilution with nitrogen) that can be used for generating additional power and then inexpensively cleaned-up with $\mathrm{CO}_{2}$ release. This stream is at high pressure (greater than $300 \mathrm{psi}$ ) and ready for $\mathrm{CO}_{2}$ sequestration if required.

Subsequently, in the Regenerator, compressed air is passed over the partially reduced OTM. This re-oxidizes OTM and releases nearly all the heat of combustion of coal. The gaseous products, now at elevated temperature $\left(1000\right.$ to $1350^{\circ} \mathrm{C}$ or $\left.1832-2462^{\circ} \mathrm{F}\right)$ and pressure (300-400 psi), are available to produce work in a combined Brayton/Rankine cycle. The principal reaction during this step is:

$\mathrm{O}_{2}$ (from air) + OTM-reduced $=$ OTM-oxidized (Highly Exothermic)

\subsubsection{Practical applications for unmixed combustion of coal}

An issue that remains to be discussed is how electric power will be generated through UMC of coal. The major energy release occurs when OTM-reduced is exposed to air and re-oxidized to OTM-oxidized in the Regenerator. One option for recovering the energy of OTM oxidation is illustrated in Figure 1-2, which shows the circulating fluidized bed system incorporated with auxiliary equipment. 


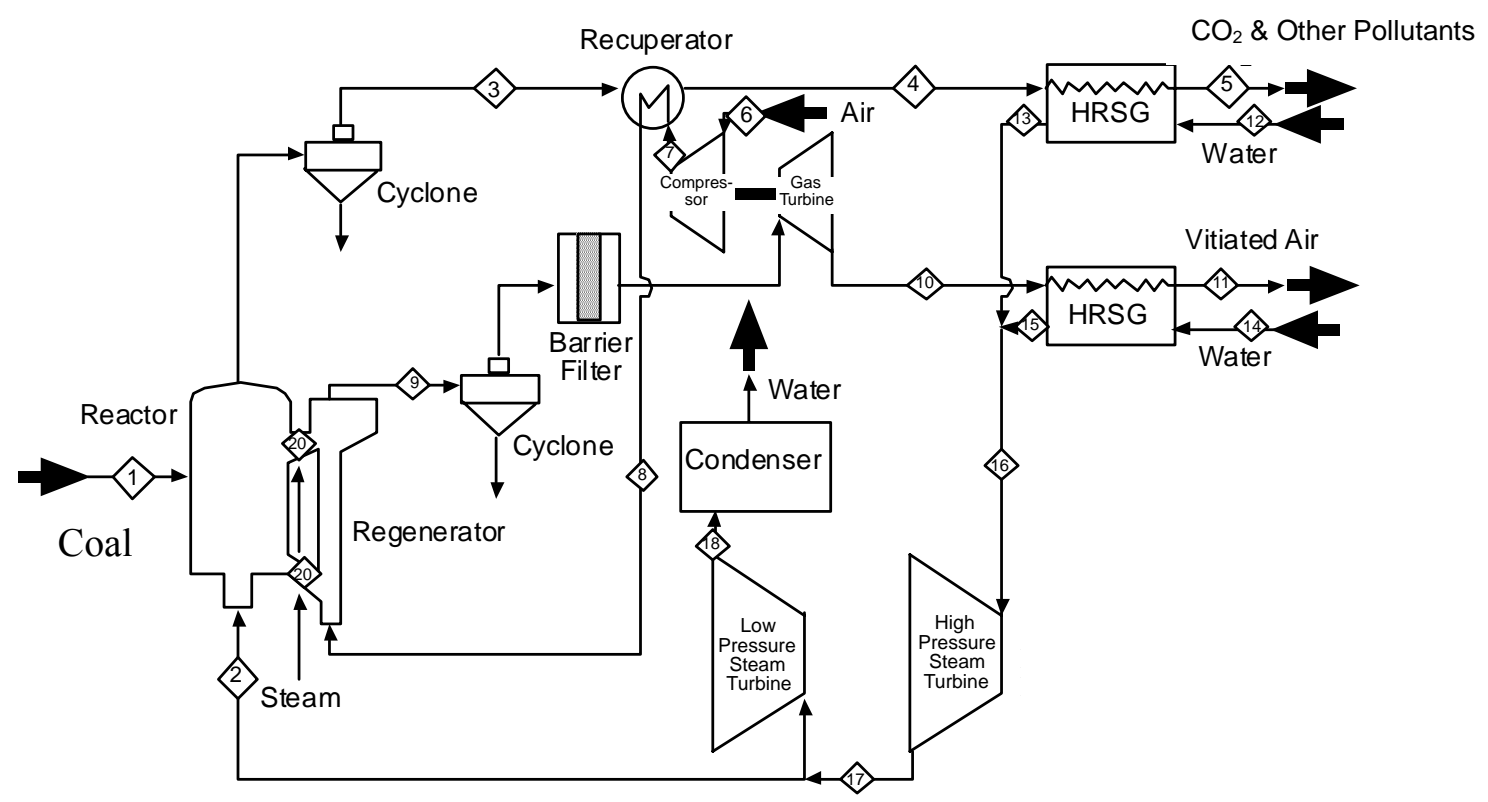

Figure 1-2 UMC based combined cycle power generation system

As shown in Figure 1-2, the gas stream leaving the Reactor first encounters a cyclone to remove ash and elutriated OTM oxides. A Heat Recovery Steam Generator (HRSG) recovers the enthalpy in the hot gases from the Reactor. The gas leaving the HRSG unit consists of $\mathrm{CO}_{2}$ and other pollutants $\left(\mathrm{SO}_{2}, \mathrm{NO}_{\mathrm{x}}\right.$ and $\left.\mathrm{Hg}\right)$ at elevated pressure, with small amounts of other impurities. After separation of water, all toxic pollutants can be sequestered along with the $\mathrm{CO}_{2}$ or can be removed by wet scrubbing or other treatment, leaving an essentially pure stream of pressurized $\mathrm{CO}_{2}$ for sequestration or discharge. Because this stream is not diluted with nitrogen, as in conventional combustion systems, the cost of this treatment should be substantially lower due to the reduction in the gas volume flow rate.

In the Regenerator, the OTM-reduced encounters a stream of preheated air. The reaction between OTM-reduced and hot air is rapid and exothermic and raises the temperature of both the vitiated air and the OTM. The OTM is conveyed by the pressurized air to the freeboard of the Regenerator where it falls into a vapor lock and is re-admitted to the Reactor at a temperature high enough to sustain the coal oxidization process. The vitiated air leaving the Regenerator is now in the range of temperatures $1000-1350^{\circ} \mathrm{C}(1832$ $2462^{\circ} \mathrm{F}$ ) and is fed to a cyclone to remove any elutriated OTM. If needed, the hot air is cooled by excess air to temperatures suitable for barrier filters to remove particles and 
then expanded across a turbine providing shaft work for electricity generation and compressing air. Excess enthalpy from the expanded and vitiated air is recovered by a second HRSG that provides high-pressure steam for fluidization, for purging the solids transfer ducts, and for use in a Rankine cycle bottoming turbine.

\section{Comparison between UMC and Other Similar Chemical Looping Approaches}

An alternative approach to coal combustion has been evaluated; one in which coal is combusted through the use of an oxygen transfer material. Alternative combustion approaches using oxygen transfer materials (also known as chemical looping processes) are under development and are compared in Figure 1-3.

\begin{tabular}{|c|c|c|c|}
\hline Company $\rightarrow$ & GE GRC & $\mathrm{TDA}^{1}$ & Tokyo Electric ${ }^{2}$ \\
\hline $\begin{array}{l}\text { Separate gasification } \\
\text { reactor required }\end{array}$ & N/A & Yes & Yes \\
\hline $\begin{array}{l}\mathrm{O}_{2} \text { plant required if } \mathrm{CO}_{2} \text { to } \\
\text { be sequestered }\end{array}$ & $\mathrm{N} / \mathrm{A}$ & Yes & Yes \\
\hline Feedstocks & Gases, liquids, or solids & $\begin{array}{l}\text { Gases } \\
\text { or } \\
\text { liquids }\end{array}$ & Gases or liquids \\
\hline Patents & $\begin{array}{l}\text { U.S. 5,339,754 (1994) } \\
\text { U.S. 5,509,362 (1996) } \\
\text { U.S. 5,827,496 (1998) } \\
\text { U.S. 6,494,153 (2002) } \\
\text { U.S. 6,669,917 (2003) }\end{array}$ & None & $\begin{array}{ll}\text { U.S. } & 5,447,024 \\
(1995) & \end{array}$ \\
\hline
\end{tabular}

Figure 1-3 Comparison of combustion approaches using oxygen transfer catalysts 
A chemical-looping combustion process was patented in 1995 by Tokyo Electric Power ${ }^{1}$ and sorbent energy transfer system is being developed by TDA, Inc. ${ }^{2}$ Even though these processes use oxygen transfer materials, they are restricted to combustion of gaseous fuels and they require a separate gasification reactor and an oxygen plant for the gasification reactor. In addition, TDA's concept requires development of a special sorbent. In comparison, GE GRC's process may not require a separate gasification reactor and may utilize inexpensive ores as the oxygen transfer catalyst. The TDA's approach for transferring $\mathrm{O}_{2}$ to gases or liquids is similar to $\mathrm{UMC}$, which was patented by GE in 1994.

\footnotetext{
${ }^{1}$ Tokyo Electric Power, U.S. Patent 5,447,024

${ }^{2}$ TDA Inc. “A Novel CO2 Separation System” DOE Contract AC26-98FT40421.
} 


\subsubsection{Anticipated benefits of technology}

There are several key advantages of this process over other advanced energy cycles that justify the technical risk involved in pursuing further development at this time. These advantages include: (i) elimination of the need for an air separation plant, resulting in decreased capital and operating costs; (ii) separation of $\mathrm{CO}_{2}$ and other pollutants $\mathrm{SO}_{2}$, $\mathrm{NOx}$ and $\mathrm{Hg}$ ) from the work cycle stream, allowing $\mathrm{CO}_{2}$ to be appropriately disposed of or utilized in a turbine to generate additional power; (iii) production of a turbine feed stream that requires minimal gas cleanup relative to existing IGCC power generation schemes; (iv) mitigation of thermal and prompt $\mathrm{NO}_{\mathrm{x}}$ formation, as Unmixed Combustion occurs at temperatures too low for $\mathrm{NO}_{\mathrm{x}}$ formation by nitrogen fixation; (v) internal generation and transfer of heat; (vi) readily available, low cost OTM is used; and (vii) the process is fuel flexible and can use different coals and potentially other fuels such as biomass.

\section{EXPERIMENTAL}

\subsection{Lab-Scale Experiments}

Southern Illinois Unversity at Carbondale (SIU), Subcontractor, led lab-scale experimental efforts. Work conducted included the design and assembly of a lab-scale externally heated tubular reactor capable of withstanding $300 \mathrm{psi}$ and $800^{\circ} \mathrm{C}$. Figure $2-1$ shows schematic diagrams of the lab-scale furnace and reactor system obtained from the PARR Company. The integrated system has valves for flow control and is instrumented for pressure and temperature measurements.
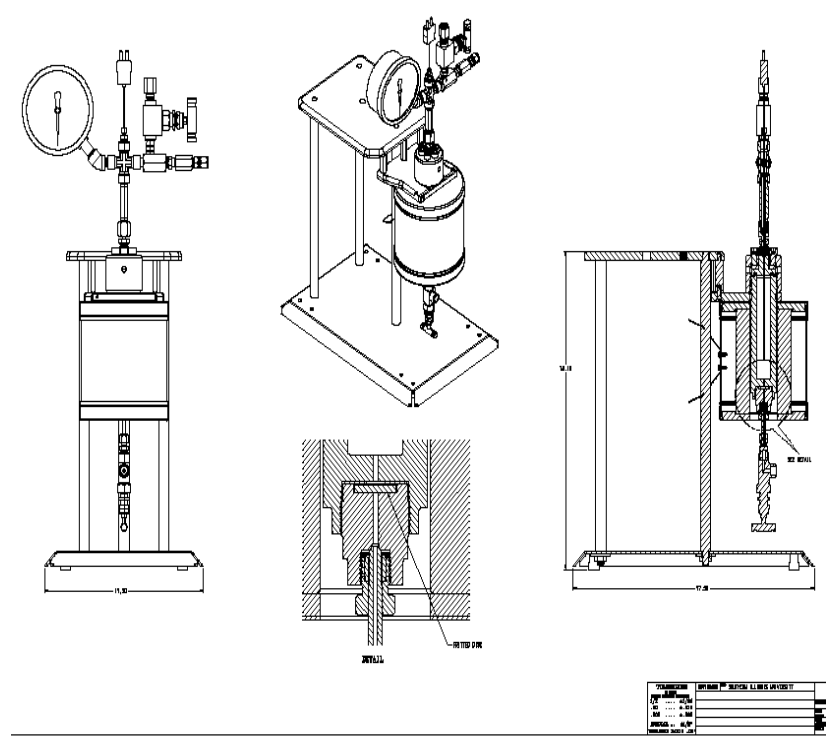

Figure 2-1 Schematic diagrams of PARR high-pressure reactor assembly. 
A photo of the delivered system is shown in Figure 2-2. The black cylindrical furnace can be lowered to allow more rapid cooling of the reactor, as shown in the figure. The inset photo shows a close-up view of the reactor, with the top inlet port surrounded by connector bolts. The bottom connector housing is also shown at the side of the main reactor.

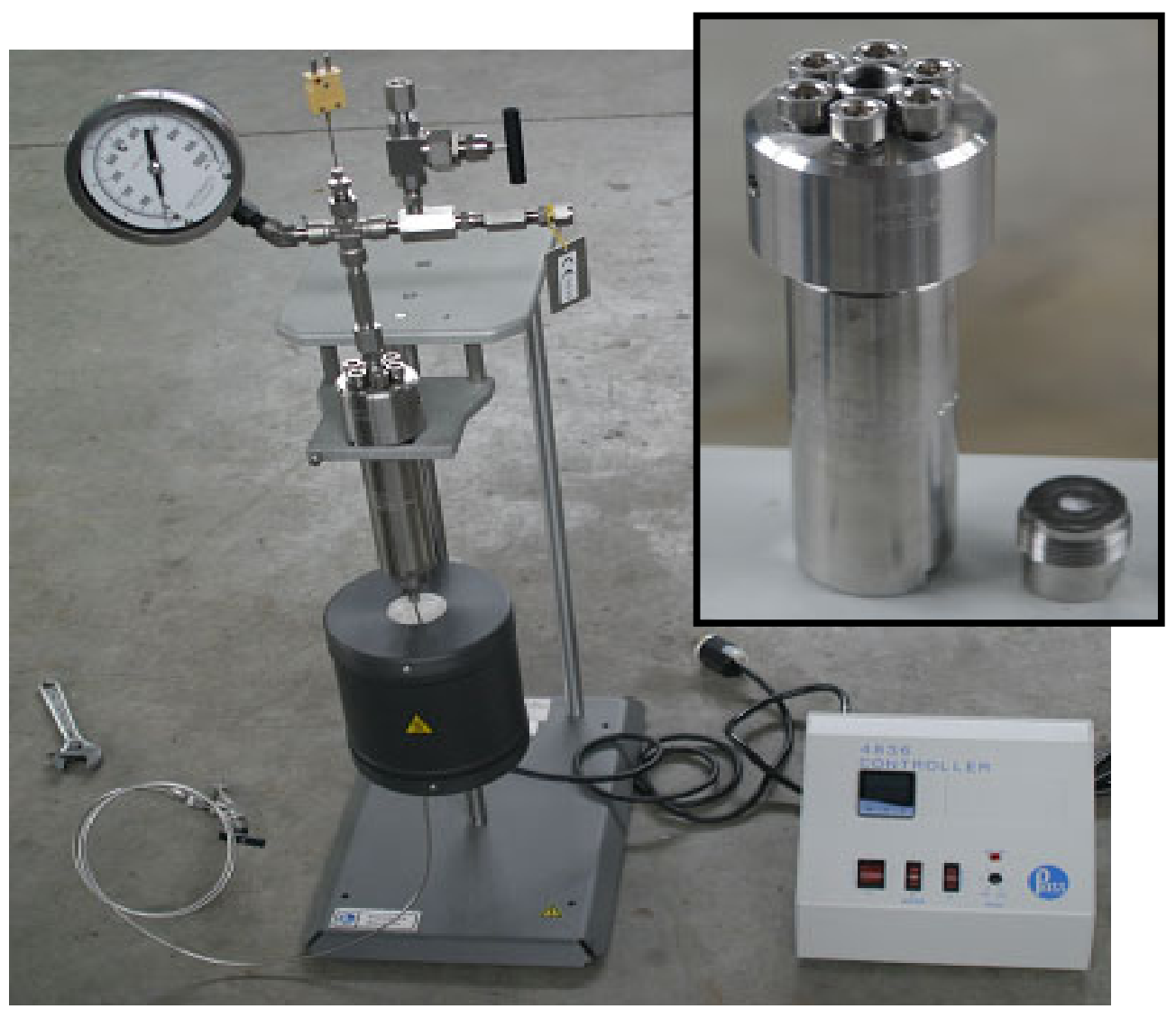

Figure 2-2 Complete high-pressure reactor, furnace and controller assembly

The testing plan included initial shakedown testing to verify the operability of the system components, as well as to characterize the residence time at different flow rates and the time required to heat up the reactor from ambient temperature. In order to obtain data relevant to specific kinetic mechanisms, simulated gas streams were fed to the reactor to represent coal gasification and char oxidation products. In addition, activated carbon was used to as simulated char for derivation of char oxidation kinetics. Dilute gas flows were used to obtain kinetic data within the timeframe of GC analysis. 
Experimental efforts conducted by SIU focused on testing the metal oxide reduction by simulated coal gasification products. Initial tests were conducted in a quartz-tube reactor at atmospheric pressure to provide baseline data for comparison with the planned highpressure experiments. A photo of the experimental system is shown in Figure 2-3, while a diagram of the system is provided as Figure 2-4.

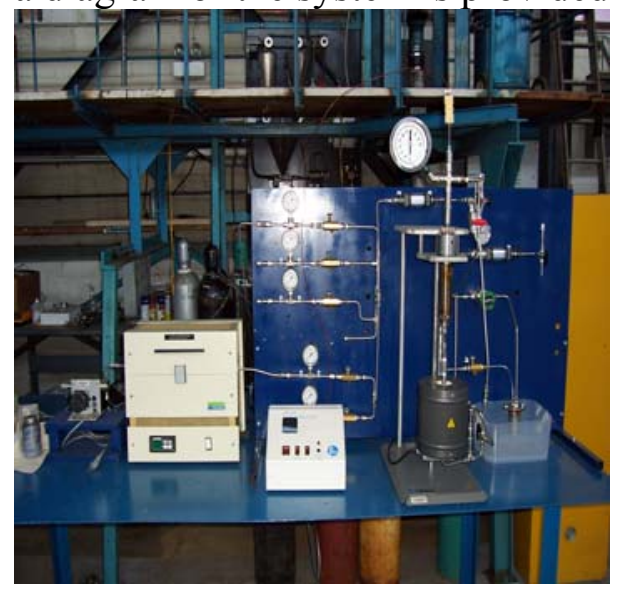

Figure 2-3 Photo of lab-scale quartz tube

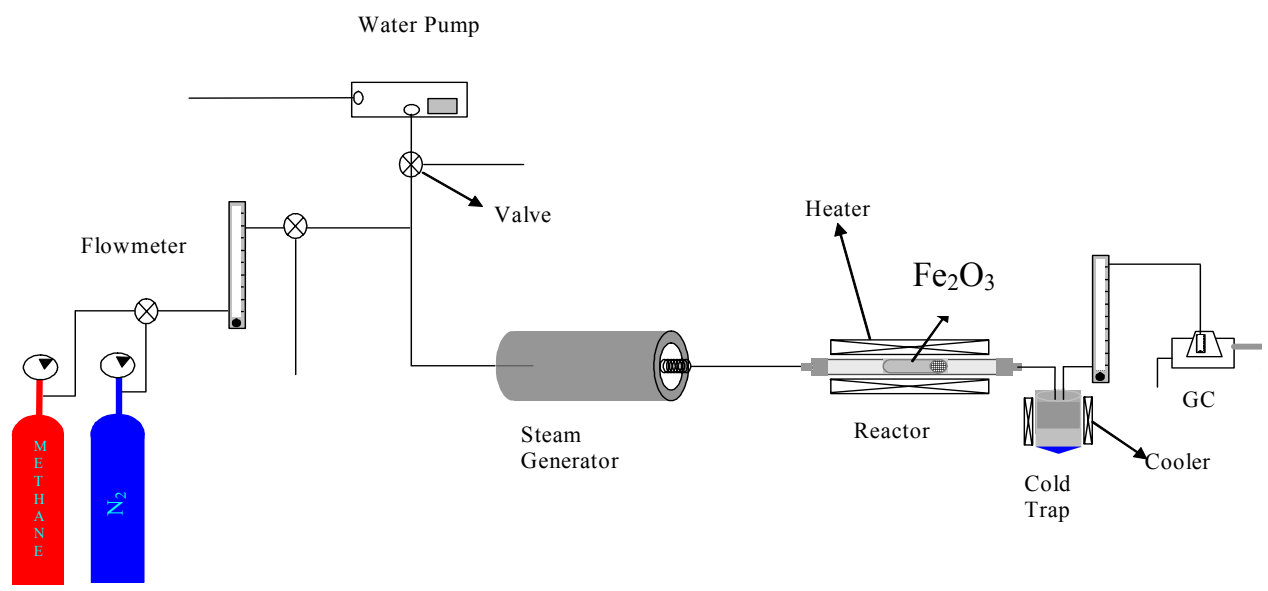

Figure 2-4 Atmospheric metal reduction tests in lab-scale quartz tube reactor

The objective of these experiments was to characterize metal oxide reduction behavior during the coal volatilization step of coal gasification. Since $\mathrm{CH}_{4}$ is a primary volatilization product, the experiments were conducted by feeding $\mathrm{CH}_{4}$ to the heated reactor (loaded with metal oxide) at temperatures between 700 and $800^{\circ} \mathrm{C} .43 \mathrm{~mL} / \mathrm{min}$ of $19 \% \mathrm{CH}_{4}$ (balance $\mathrm{N}_{2}$ ) reactant gas was fed.

\subsection{Pilot Scale System}

The main activities for the pilot scale system task included system design, fabrication and assembly. Reactor system created in a previous program was used as the basis for the reactor designs. A series of design modifications were made to reduce heat loss and 
improve fluidization conditions. After system fabrication and assembly was completed and a series of system shakedown testing and experiments were carried out.

\subsubsection{System design and engineering}

\section{Dense Phase Solid Circulation Testing}

Cold flow model testing was conducted to assess the viability of a dense-phase solids transfer method for bed circulation previously described in the second Semiannual Report (November 2004). The experimental setup of the dense-phase transfer system is shown in Figure 2-5. Red arrows indicate the direction of solid particles along transfer ducts, while blue arrows indicate the injection points for fluidization gas $(\mathrm{F} 1=200 \mathrm{cfh})$ and aeration gas (F2=300cfh).

Assessment of the dense-phase solids transfer system showed gravity to be a relatively weak driving force for circulation of solid particles between two fluidized beds. Although the fluidized beds were well agitated, (200 cfh fluidization flow) solid particles did not circulate. Aeration gas was gradually increased up to $300 \mathrm{cfh}$, but the increase did

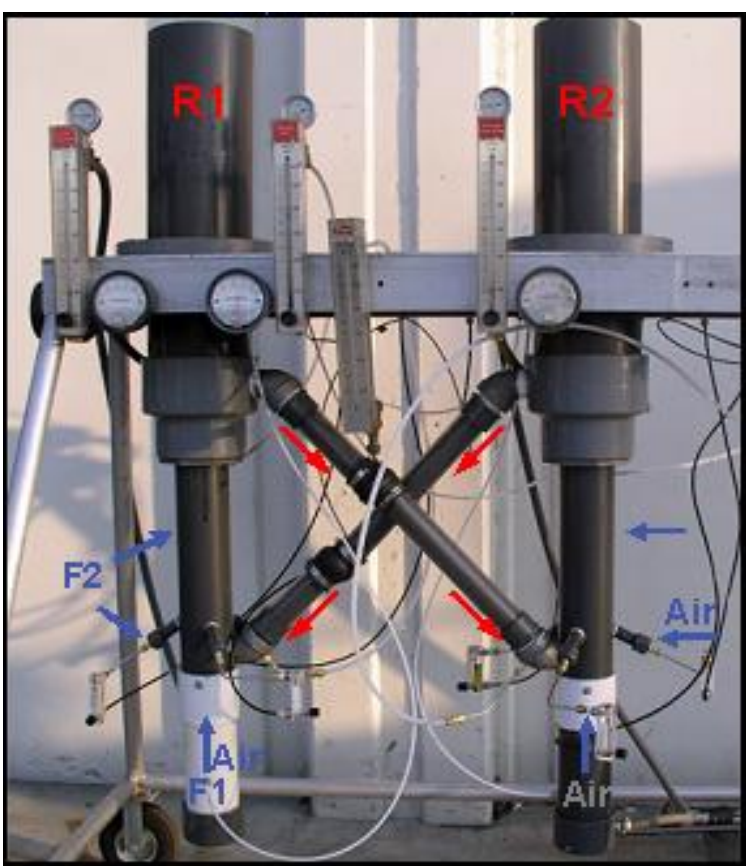

Figure 2-5 Experimental setup for PYROX process evaluation. not cause the solid particles to circulate through the transfer ducts. The aeration flow was not increased beyond $300 \mathrm{cfh}$ because in the current pilot scale experimental unit, the aeration gas cannot exceed the fluidization flow; thus $300 \mathrm{cfh}$ is a practical flow rate limitation. Due to this limitation, the effective bulk density of the bed could not be reduced any further. Periodically, the distributor plate and plenum assembly (white sections at the bottom of each reactor in Figure 2-5) were removed for internal inspections. The reactor contents flowed freely from the transfer ducts, indicating that no plugging had occurred in the transfer ducts.

The testing results indicated that the downward force component, $\left(\mathrm{m}_{\text {solids }} \mathrm{gDh}\right)$ from the solids in the transfer legs was not sufficient to achieve flow from the transfer duct into the fluidized bed to initiate circulation. As a result, a dilute-phase solids transfer method was implemented for pilot-scale testing. This method uses steam as a carrier gas, entraining 
solids for transfer between reactors, and was tested previously during UMC experimental efforts (as described in the first Semiannual Report-April 2004).

\section{Reactor Design}

The existing reactors and associated solids transfer system used in a previous development program were the basis for the reactor designs, and areas of improvement were identified based on a limited experimental testing. The driving force for modification of the reactors is the need to reduce the excessive heat losses identified during the previous experimental program. Detailed analyses were conducted to identify potential causes and solutions, and two separate reactor designs were completed to address the heat transfer issues. The designs were evaluated using Solid Works ${ }^{\text {TM }}$ threedimensional modeling software. This software has the capability to produce detailed models that can be rotated in all directions, and accurately depict the geometry of the ducts connecting the reactors; particularly the angle at which the solids transfer ducts penetrate the reactor shell and insulation. The location of the two solids transfer duct assemblies must be closely coordinated, as the refractory thickness limits access to the center of the reactor.

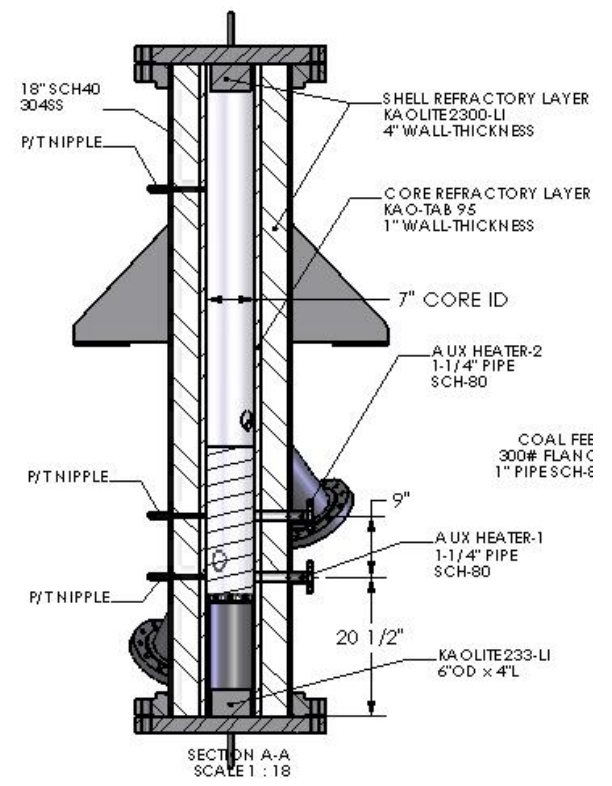

Figure 2-6 Cross-sectional view of UMC-Coal reactor. 
Several improvements to both reactors were made to address previously encountered problems. Two key improvements can be seen in Figure 2-6, which shows a cross-section of Reactor 1 (Reactor 2 is similar). First, the insulation layer (Kaolite 2300-LI) was doubled to 4" in thickness to reduce heat losses. This caused a reduction in the reactor inner diameter to 7'. Second, two 1-1/4" access ports were added for an auxiliary heating system, mainly to be used during start-up. The size of these ports provides great flexibility for use of various heating methods. For example a concentric feeding probe could be used for combustion gases or an electric cartridge heater could be inserted. Other improvements included enlargement of the coal feeding port to 1" for increased accessibility and the use of a single refractory layer along solids transfer ports to minimize heat losses. Despite all these changes, the thickness of the inner abrasionresistant refractory layer was relatively unchanged.

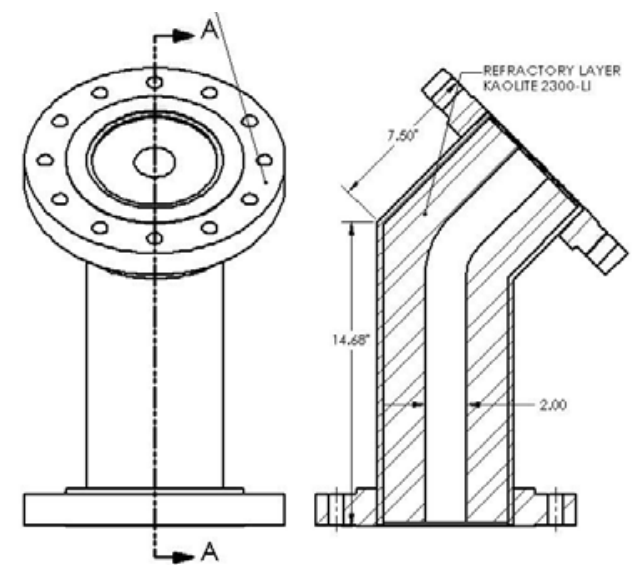

Figure 2-7 Solids transfer duct drawing.

Refractory casting inside the transfer ducts was also improved. The streamlined refractory layer now has a $45^{\circ}$ sweep, which replaces the formerly sharp transition (see Figure 2-7). This feature reduced wear and likelihood of particles plugging. A protective layer was applied to protect the inside surface from particle abrasion. 


\subsubsection{Heat transfer assessment}

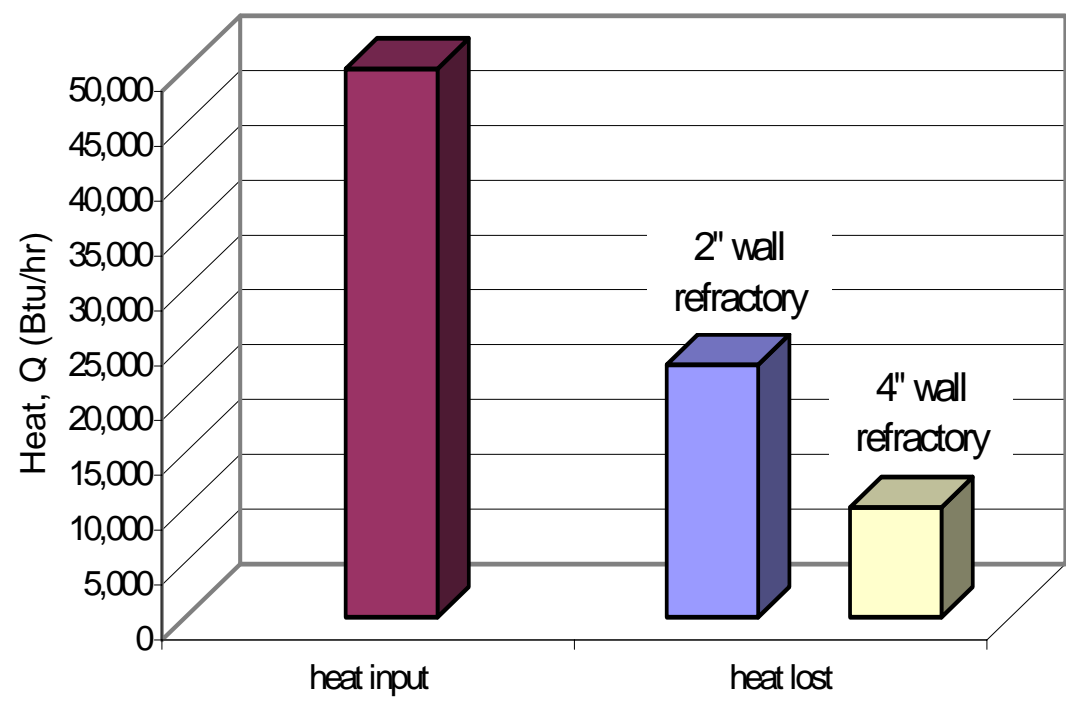

Figure 2-8 Pilot-scale reactor heat losses

An updated heat transfer model was benchmarked using experimental data from the previous experimental program. The results showed that additional refractory insulation could reduce the heat loss from the reactor. These results were quantified as shown in Figure 2-8, which shows the heat input compared to the heat loss for two different refractory wall thicknesses. The reactors previously had 2 inches of insulation, resulting in nearly $50 \%$ heat loss. It is shown in this figure that increasing the refractory thickness to 4 inches significantly reduces the heat loss. Using the existing reactor shells, 4 inches of insulation provides a reactor with a 7-inch inside diameter. Detailed fluidization calculations were also conducted to assess the required fluidization flow rates, coal flow rates, and bed volumes associated with this change in reactor size.

The bed volume was selected to provide the height necessary to reach the top solids transfer duct. This bed volume was coupled with bed reactivity and residence time data to establish the coal feed rate that would allow steady-state operation. This coal feed rate is being used in evaluating coal delivery options, including the continued use of a coal slurry feed. A separate sensitivity analysis was conducted to quantify the impact of slurry water content on reactor temperature, and this information was used for final selection of a coal delivery method. Bed fluidization behavior is also affected by the change in reactor diameter. Using a target volumetric flow rate equal to $1 \frac{1}{2} * \mathrm{mfv}$ (minimum fluidization velocity), calculations identified the mass flow rates of air and steam required to maintain a constant volumetric flow rate at each heat-up, pressurization and operation stage. These flow rates were compared to the operating ranges of all 
associated instrumentation, and were found to be within the existing equipment specifications.

\subsubsection{Reducing heat loss through additional insulation}

A baseline reactor design was developed that differs from the previous design primarily in the inclusion of additional insulation. Four inches of insulation (rather than the twoinch thickness used previously) leads to a reactor with a 7" inside diameter. A crosssectional view of this baseline design is shown in Figure 2-9. The two reactors are composed of 18 " diameter 340SS pipe with 300-lb flanges at each end. The locations of ports for coal feeding; pressure and temperature instrumentation; feed delivery and product exit are shown. The method of solids circulation between reactors is also shown (the cross-sectional view shows only one of the two transfer leg assemblies).

This design makes use of the dense-dilute phase method for solids transfer, in which the solids exit the bottom of the reactor bed in a gravity-fed dense phase, and then are propelled into the top of the second reactor bed using a steam carrier gas that creates a dilute phase of bed materials.

The generation of heat in the regeneration reactor and heat transfer via the circulation of hot bed solids is an important aspect of this technology. The carrier gas used for the dilute phase transfer has been demonstrated to exert a cooling effect on the bed materials during transfer. In order to address this issue, a modified reactor design was developed, as described below. 


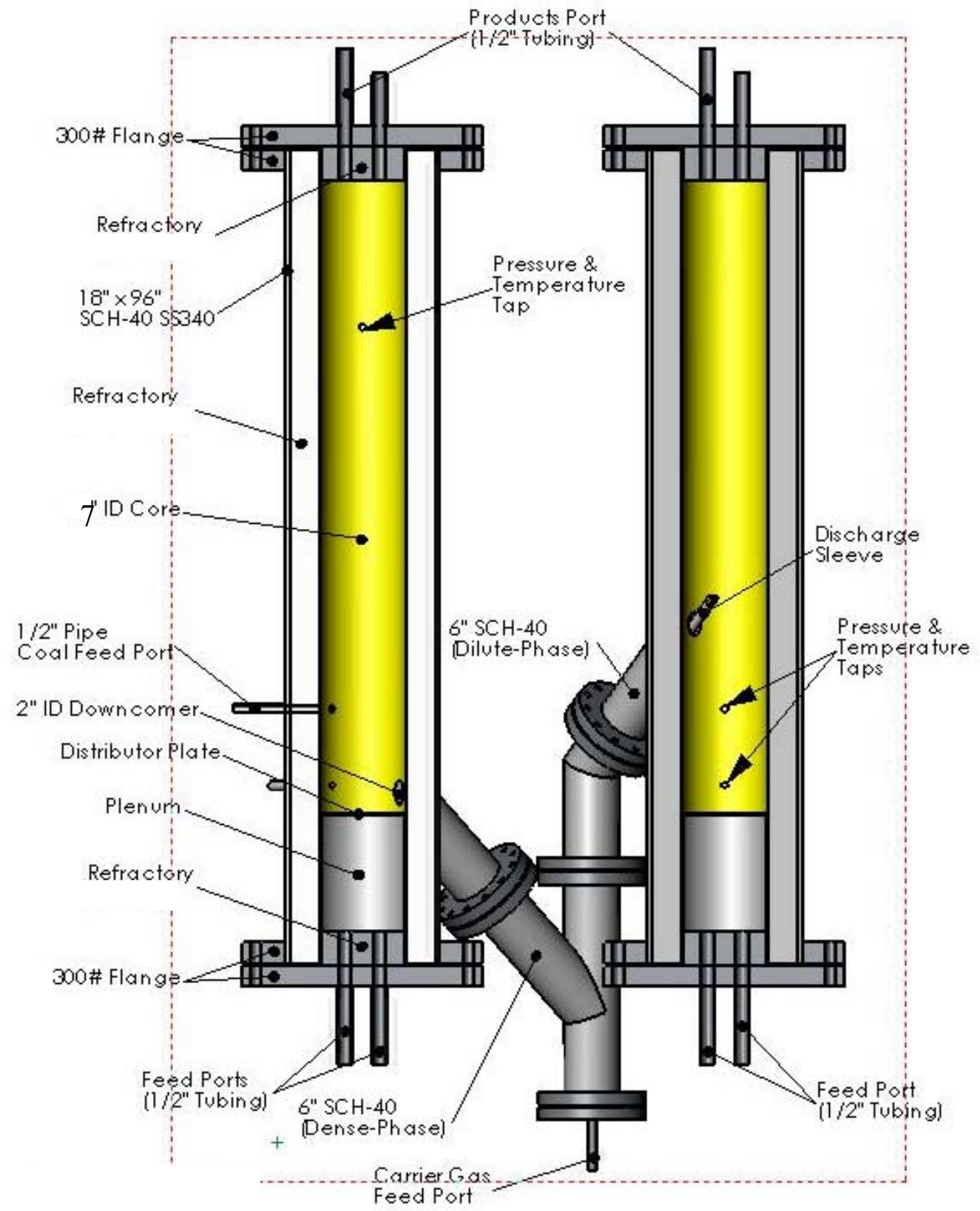

Figure 2-9 Cross-sectional view of baseline pilot-scale reactor. 
A supplier for the metal oxide bed materials was identified, and a representative sample of bed materials was obtained and subjected to sieving for particle size analysis. Figure 2-10 is the particle size distribution for the sample, which showed that the majority of the particles were between 251 and $420 \mu \mathrm{m}$. The fraction of particles less than $105 \mu \mathrm{m}$ was $<5 \%$ and this prevented significant amount of the bed materials from being lost through entrainment. This information provides a baseline for comparison with used bed materials, and would allow an assessment of attrition based on shifts in the particle size distribution.

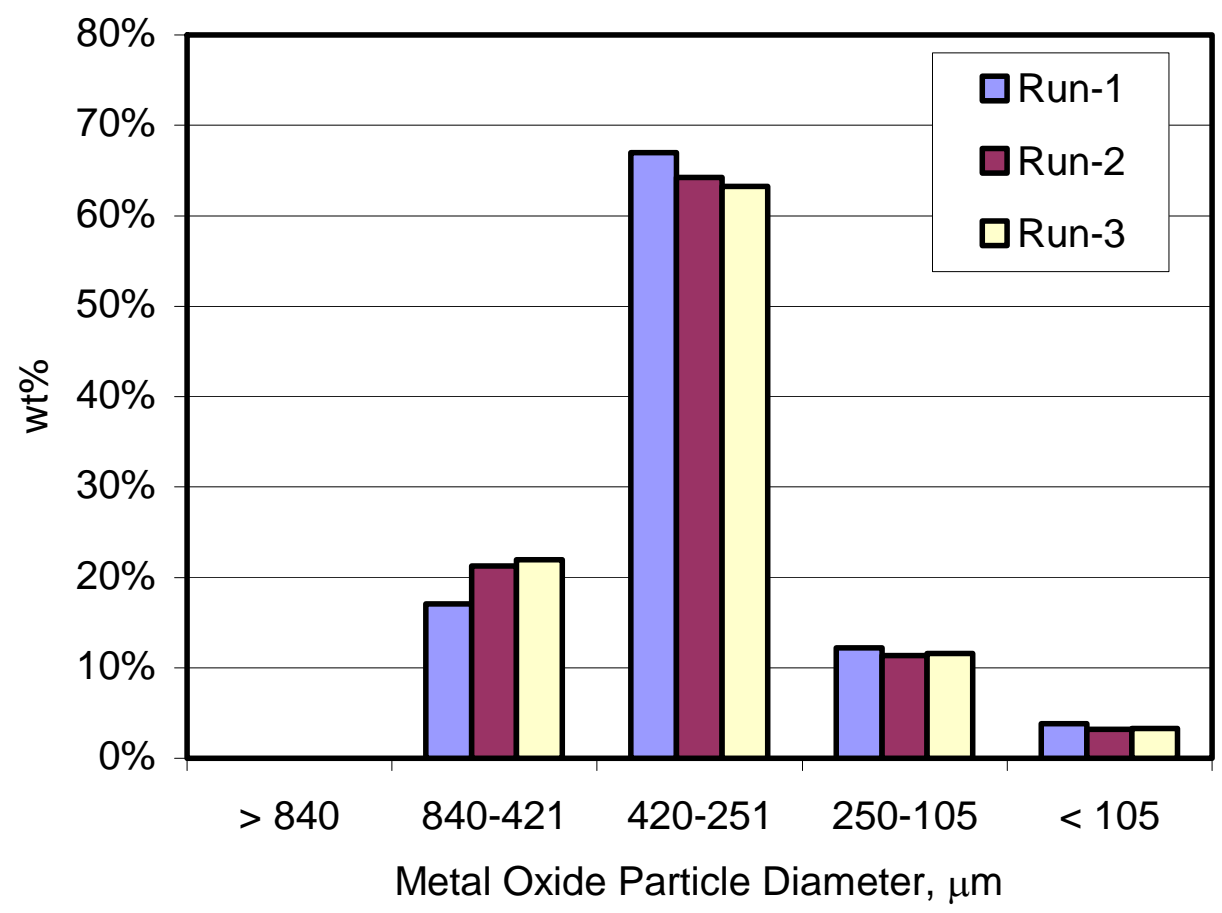

Figure 2-10 Particle size distribution of metal oxide.

(2) Coal Feeding System

A number of engineering upgrades were implemented to improve feed reliability at startup. The previous system is shown in Figure 2-11, which indicates two of the major problems encountered. 
First, during slurry recirculation, prior to coal-feeding (as seen Figure 2-11) a small section upstream of the feed valve would fill with coal. Subsequently, when switching to feed mode, the coal would compress due to the high-pressure differential and plug the line, blocking the flow of coal slurry into the reactor. Second, bed material and steam would fill the coal feed line between the reactor and feed valve. This mixture caused plugging when the coal slurry was fed.

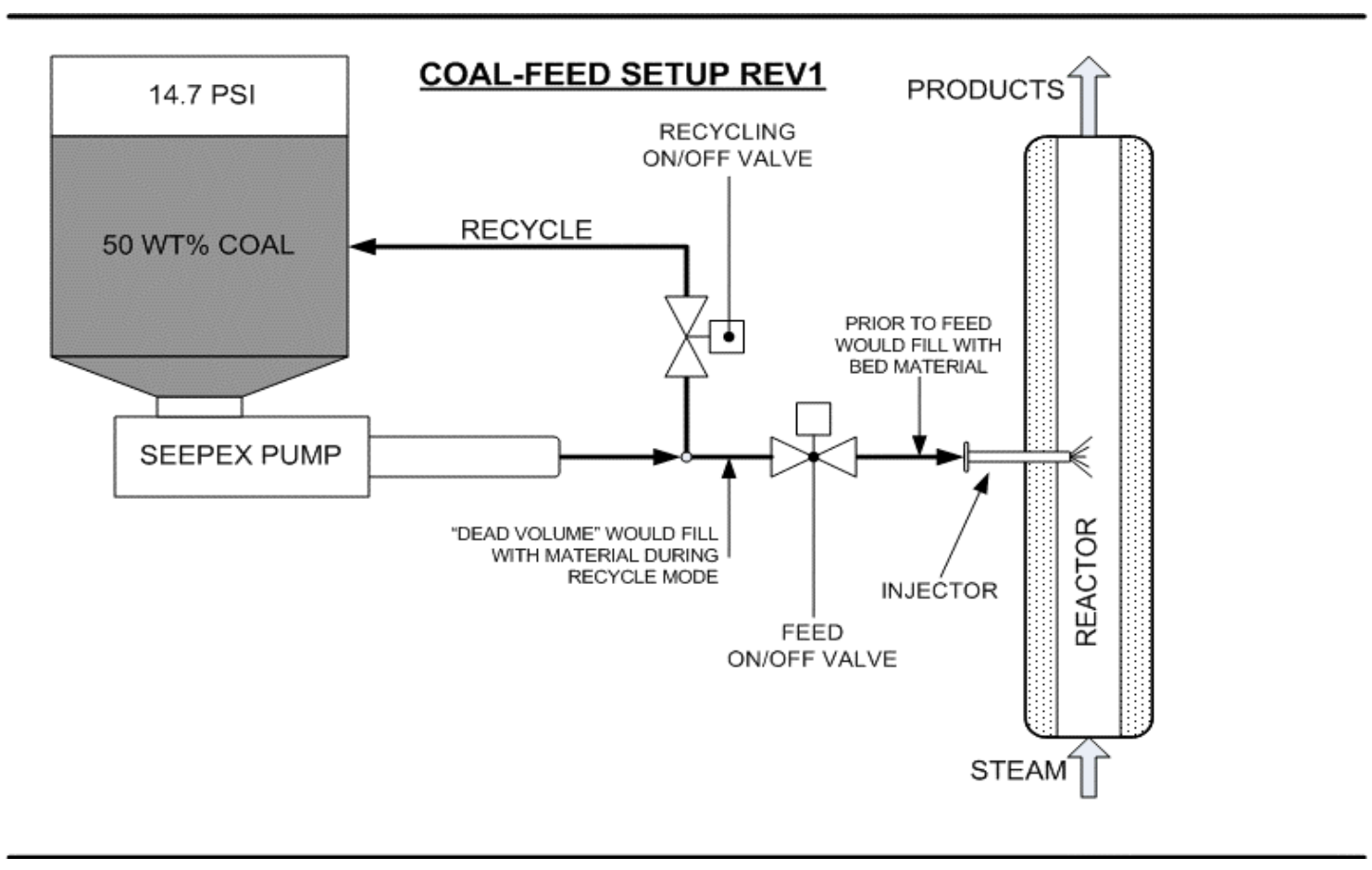

Figure 2-11 Previous coal feeding system.

Improvements to the coal slurry system are shown in Figure 2-12. The upgrades shown in green were developed to address the difficulties previously encountered. These include minimizing the "dead volume" by replacing the feed and recycle valves with a three-way valve. A tapered transition at the pump exit was added to prevent accumulation of coal. A $\mathrm{N}_{2}$ purge system was implemented to clean the line between the reactor and the threeway valve. In addition, the diameter of the coal feed probe was reduced to increase the linear velocity, in turn reducing the likelihood that water will flash vaporize before the slurry enters the reactor. 


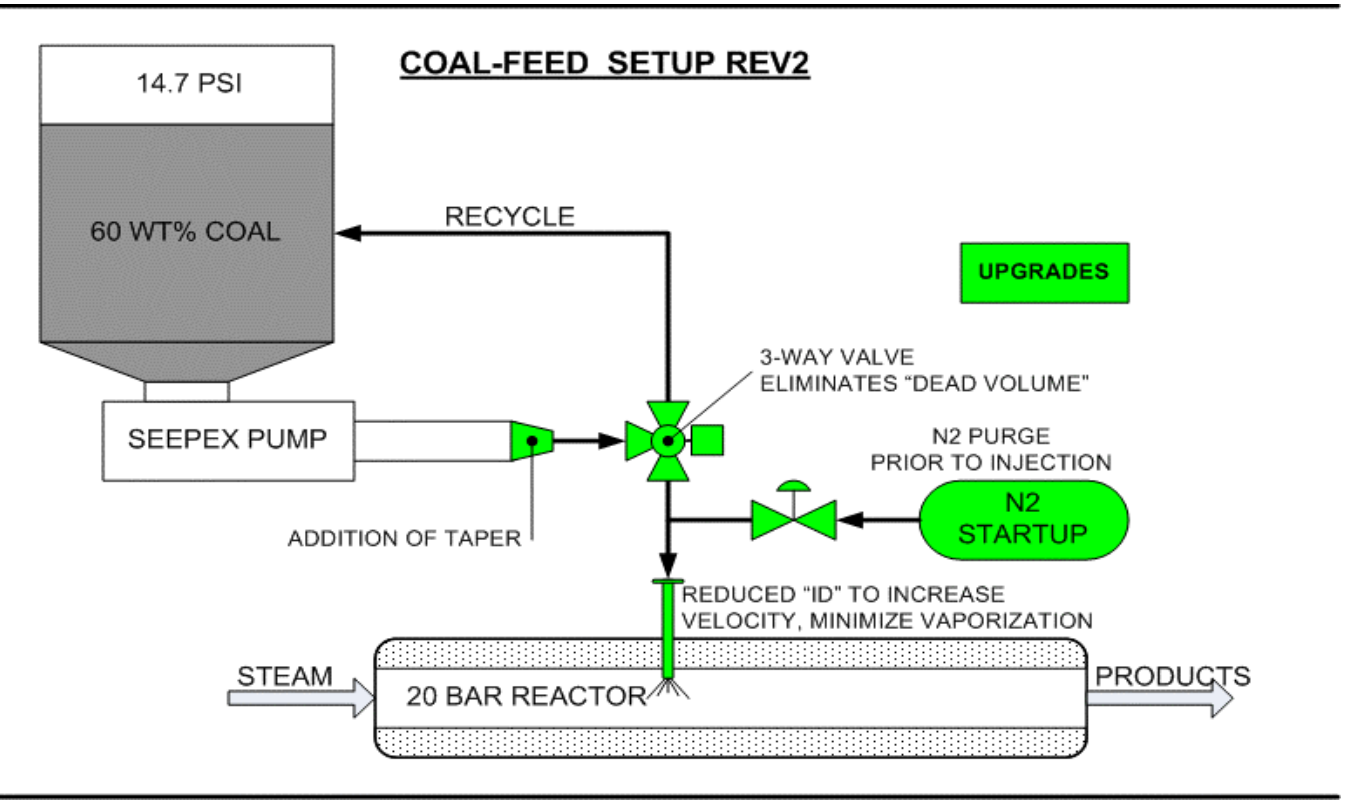

Figure 2-12 Revised coal feeding system with upgrades shown in green.

\subsubsection{System fabrication, assembly and shakedown}

\section{(1) Reactor Fabrication}

The reactor refractory was cast according to the design described previously. A picture of the top of a reactor with the thicker refractory can be seen in Figure 2-13.

\section{Distributor Plate Fabrication}

An outside vendor fabricated the distributor plate nozzles. 800 and 900 $\mu \mathrm{m}$ holes were laser-drilled in each nozzle, and they were welded to the distributor plate by the in-house machine shop. The distributor plates were installed in the reactors prior to loading the bed materials.

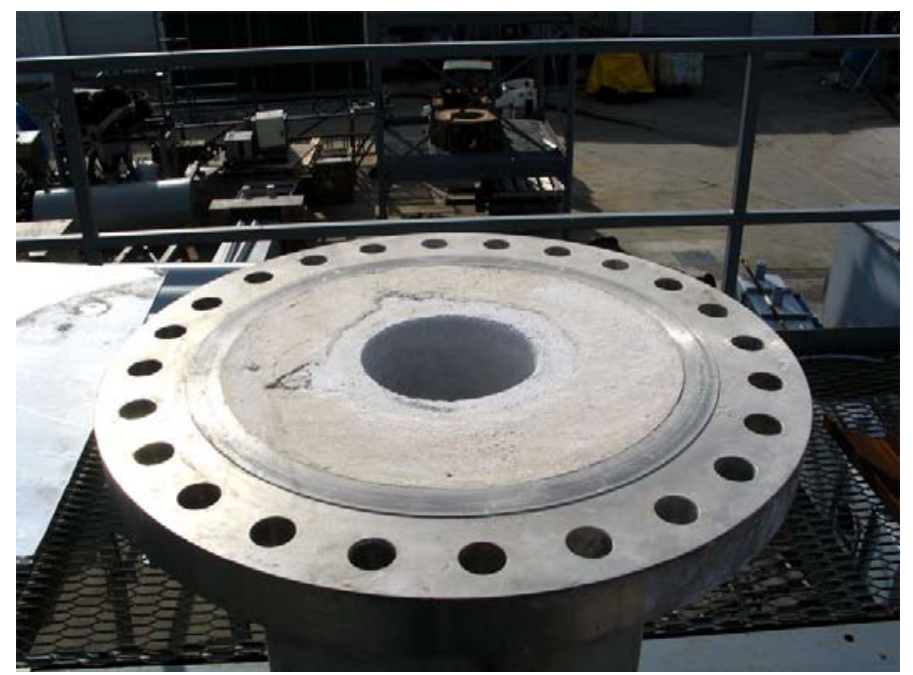

Figure 2-13 Photo of Reactor 1 refractory layers. 
(3)

System Assembly

Despite delays in the approval of city and fire department permits to construct the new GE testing facility in Santa Ana, relocation and assembly of core components was completed in February 2005. A photo of this milestone is provided in Figure 2-14. Note that structural permits were needed to place the reactors on their frame, thus the reactors are not shown in this picture. All permits were approved at the end of March 2005.

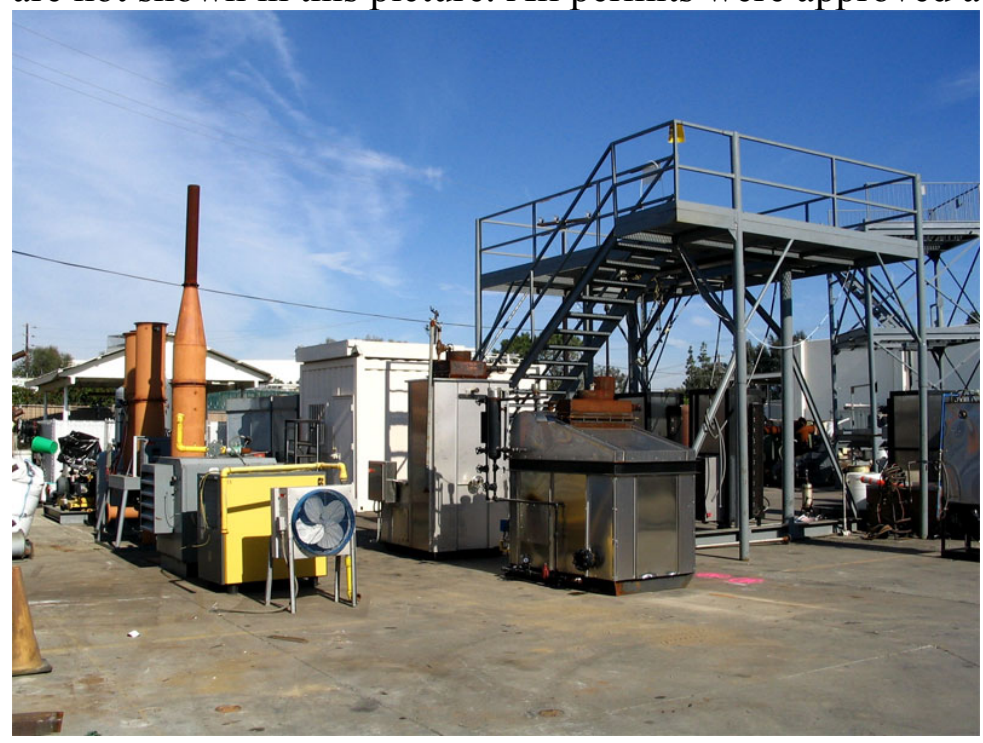

Figure 2-14 Photo of facility with assembled core components

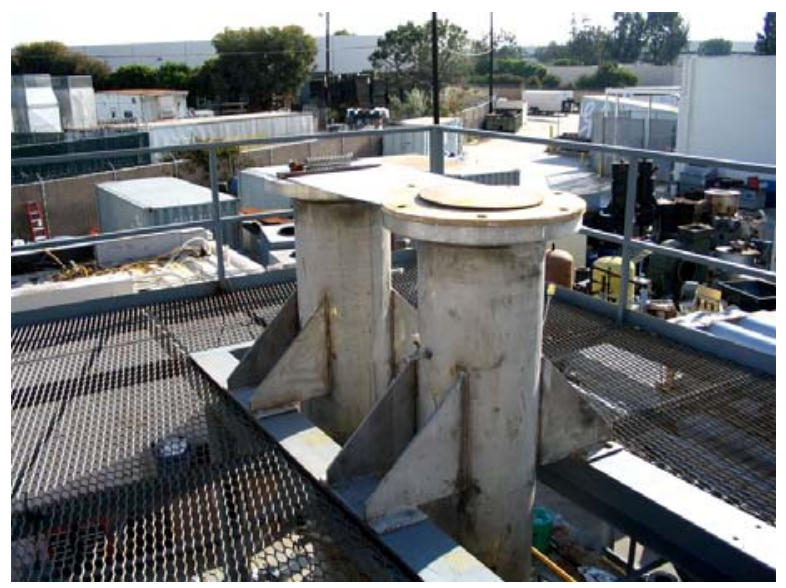

Figure 2-15 Photo of reactors shown assembled on support frame--top view 
Soon after approval of the structural permits in early March both reactors were assembled on the frame as can be seen in Figures 2-15 and 2-16. The test stand surrounding the frame, shown in Figure 16, has also been upgraded. Engineering improvements were developed during December 2004 and reviewed in early January 2005.

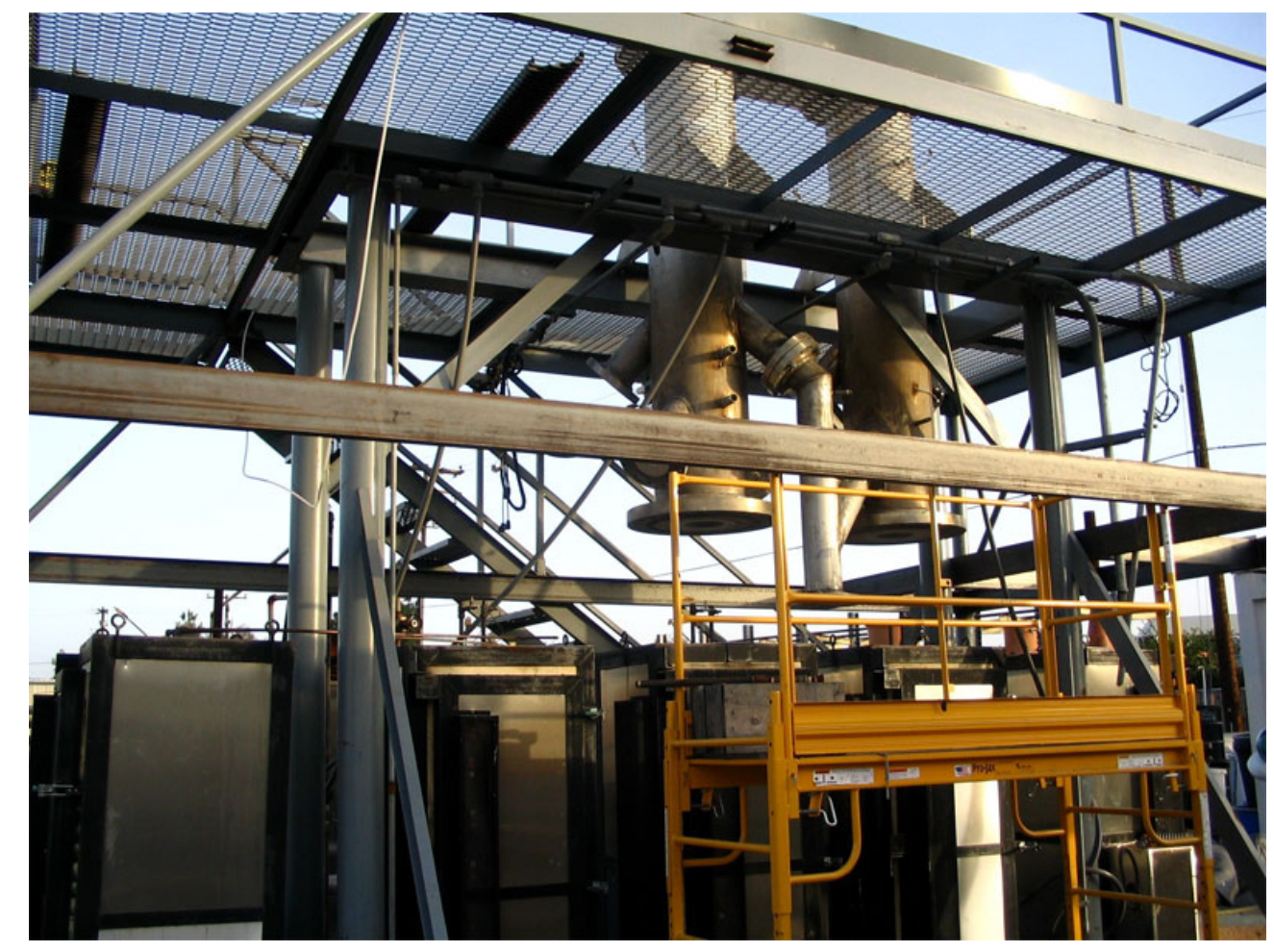

Figure 2-16 Photo of reactors shown assembled on support frame- bottom view

\section{Coal Feeding System}

Limited shakedown testing of the modified slurry feed system was conducted. The modified setup was tested successfully offline and was able to maintain $10 \mathrm{lb} / \mathrm{hr}-35 \mathrm{lb} / \mathrm{hr}$ of continuous slurry flow. The calibration curve for the pump is provided in Figure 2-17, with experimental data obtained using the upgraded coal feeding system. 

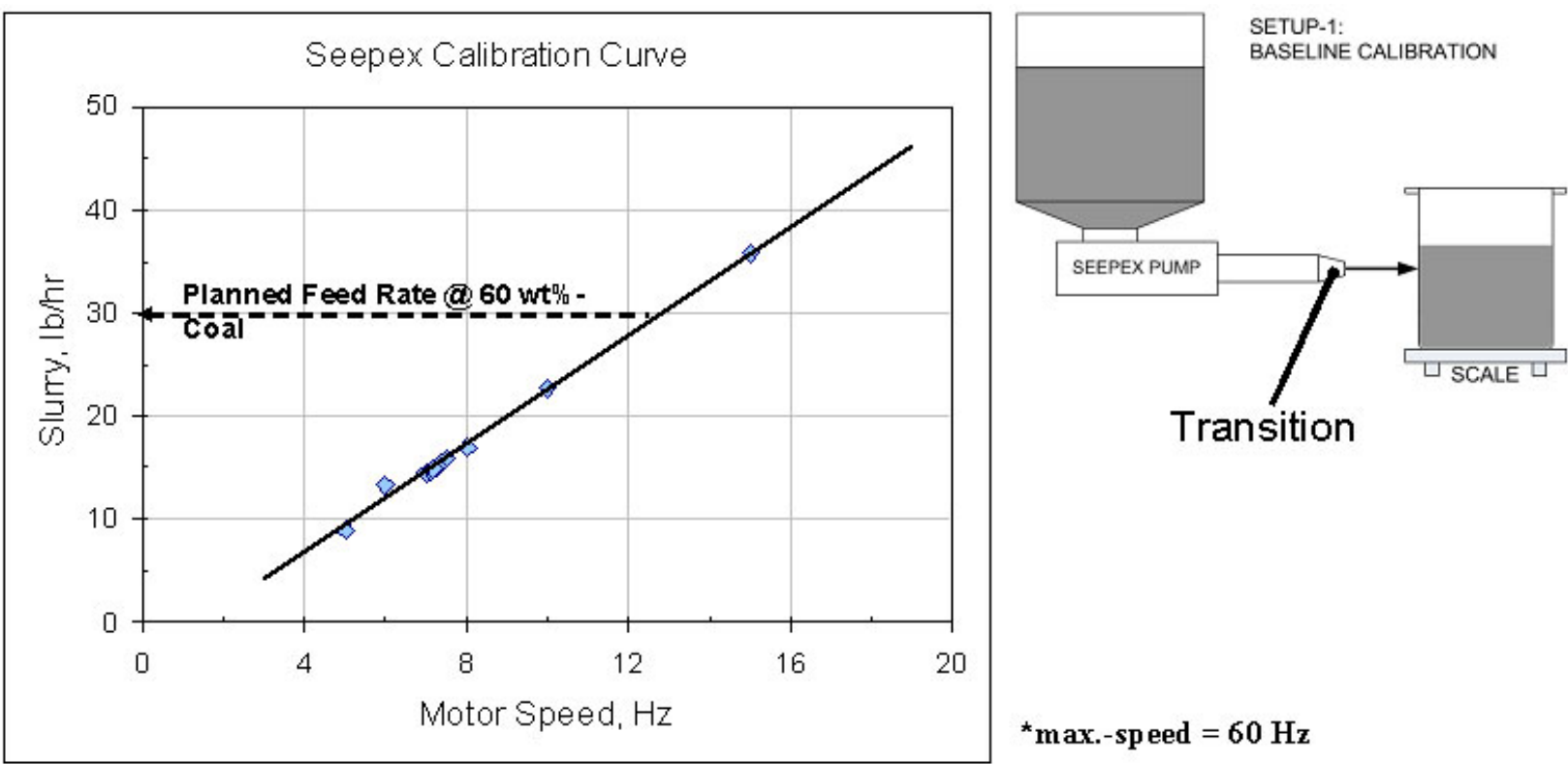

Figure 2-17 Coal slurry calibration curve from upgraded coal feeding system. 


\section{EXPERIMENTAL RESULTS AND DISCUSSION}

\subsection{Lab Scale Results}

Coal gasification tests were conducted by SIU in a fixed bed in a controlled temperature furnace using Utah Bituminous coal. The parametric tests summarized below include investigations of the impact of temperature, steam flow rate and coal:OTM ratios on coal gasification performance. These results provided both quantitative and qualitative information about coal gasification behavior.

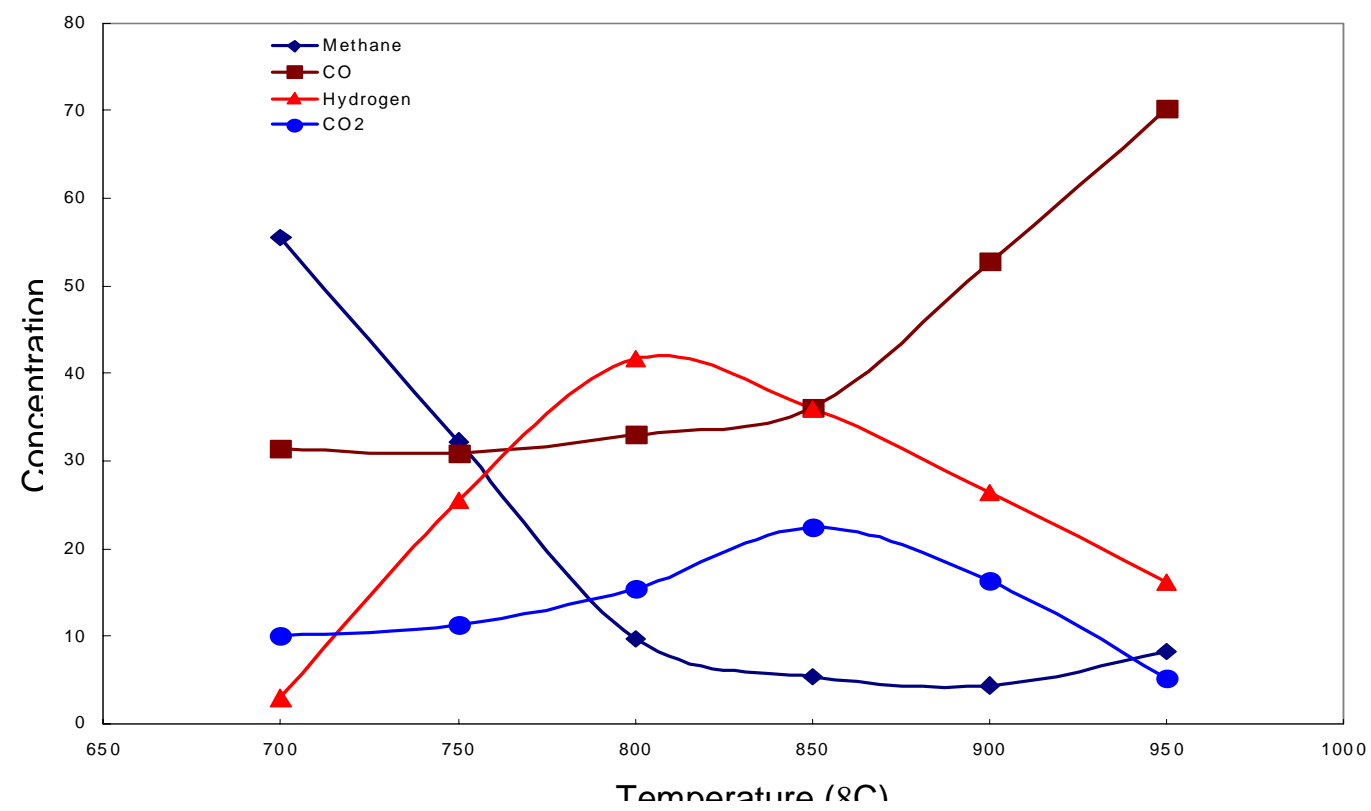

Figure 3-1 Coal gasification product gas composition at different temperatures.

Figure 3-1 shows the temperature dependence of product gas compositions during baseline coal gasification tests conducted with $1 \mathrm{ml} / \mathrm{min}$ of water in a fixed bed of coal. The methane $\left(\mathrm{CH}_{4}\right)$ concentrations were at their lowest values in the temperature range of $850-900^{\circ} \mathrm{C}$. The desired gasification temperature was selected by consideration of the $\mathrm{CH}_{4}$ and $\mathrm{CO}$ concentrations; $\mathrm{CH}_{4}$ concentrations dropped at temperatures above $800^{\circ} \mathrm{C}$, while $\mathrm{CO}$ concentrations climbed above $850^{\circ} \mathrm{C}$. Thus, the temperature range between 800 and $850^{\circ} \mathrm{C}$ balanced achieving good $\mathrm{CH}_{4}$ conversion with avoiding excessive $\mathrm{CO}$ formation.

The importance of the steam:carbon ratio is illustrated in Figure 3-2 for tests conducted at $800^{\circ} \mathrm{C}$. $\mathrm{CH}_{4}$ slip is most pronounced when no steam is present, and $\mathrm{CO}$ levels are highest at water flow rates of 0.5 and 0.75 . At a water flow rate of $0.5 \mathrm{ml} / \mathrm{min}$, both the $\mathrm{CO}$ and 
$\mathrm{CO}_{2}$ concentrations increased while the $\mathrm{H}_{2}$ and methane concentrations decreased. Steam reforming of coal and dry reforming of methane both took place in this regime. The $\mathrm{H}_{2}$ concentration is reduced primarily due to methanation reactions. At a water flow rate of 1 $\mathrm{ml} / \mathrm{min}$, the $\mathrm{CO}$ content decreased, while the $\mathrm{H}_{2}$ content increased; indicating that watergas shift reactions were beginning to dominate. Based on the behavior observed, 1.0 $\mathrm{ml} / \mathrm{min}$ appeared to be a minimum threshold for good coal gasification performance. Above a water flow rate of $1.3 \mathrm{ml} / \mathrm{min}$, the performance levels off, suggesting that excessive steam has a negligible impact on system performance (although the energy requirement for steam production has a negative impact on overall efficiency).

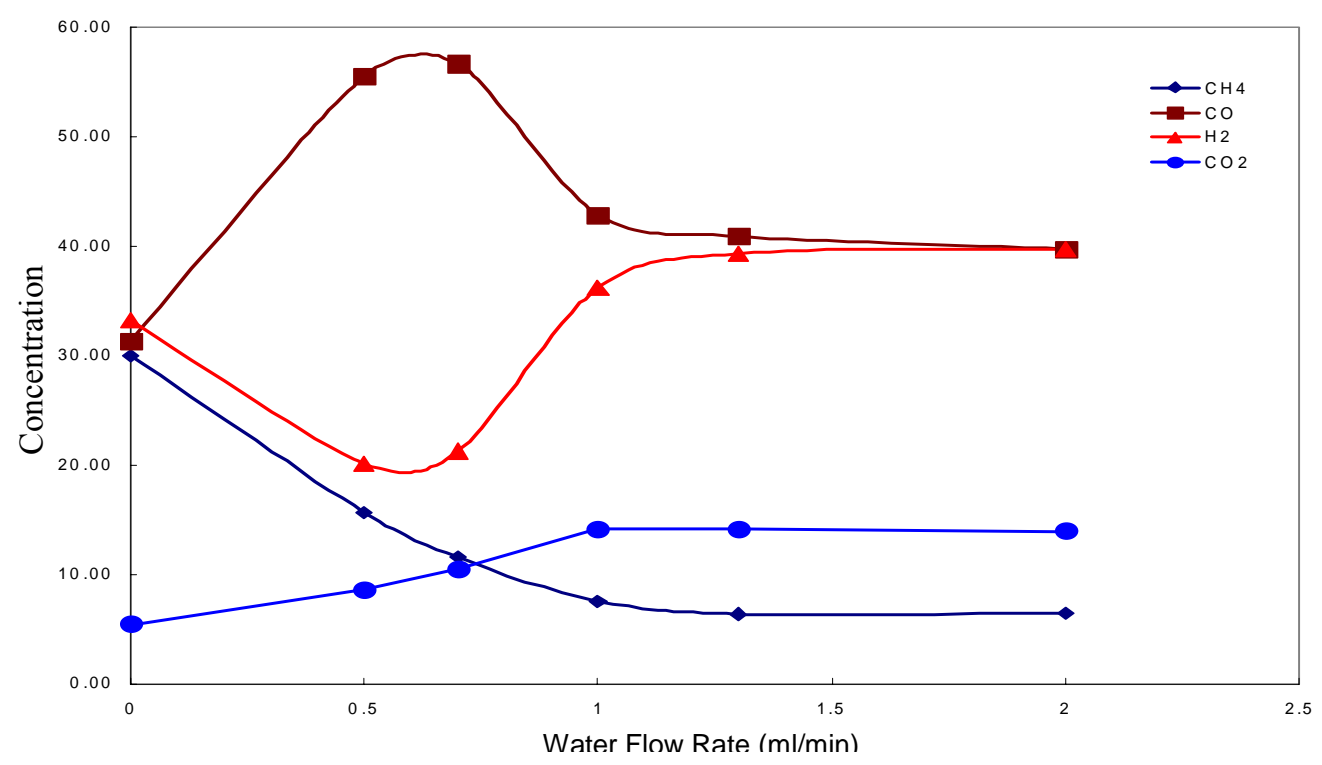

Figure 3-2 Product gas composition Vs steam flow rates

The amount of OTM present during gasification has also been identified as a key variable. Results of gasification tests conducted at $800^{\circ} \mathrm{C}$ with $1 \mathrm{ml} / \mathrm{min}$ of water for a range of OTM:coal ratios. Figure 3-3 shows that for OTM:coal ratios less than about 4, $\mathrm{H}_{2}$ and $\mathrm{CO}_{2}$ concentrations increased with increasing OTM:coal ratios. At OTM:coal ratios greater than 4 , a decrease in $\mathrm{H}_{2}$ concentration was observed.

It is known that some OTM have a catalytic effect on the water-gas shift reaction, which tends to increase $\mathrm{H}_{2}$ and $\mathrm{CO}_{2}$ production. In contrast, $\mathrm{H}_{2}$ (or $\mathrm{CO}$ ) can be consumed by OTM reduction reaction. At low OTM:coal ratios, the catalytic effect appears to dominate, as evidenced by the increased $\mathrm{H}_{2}$ concentrations. At higher OTM:coal ratios, OTM reduction reactions appear to consume a significant amount of $\mathrm{H}_{2}$, resulting in lower $\mathrm{H}_{2}$ concentrations. This information aids the selection of initial reactor bed volumes to ensure good performance. 


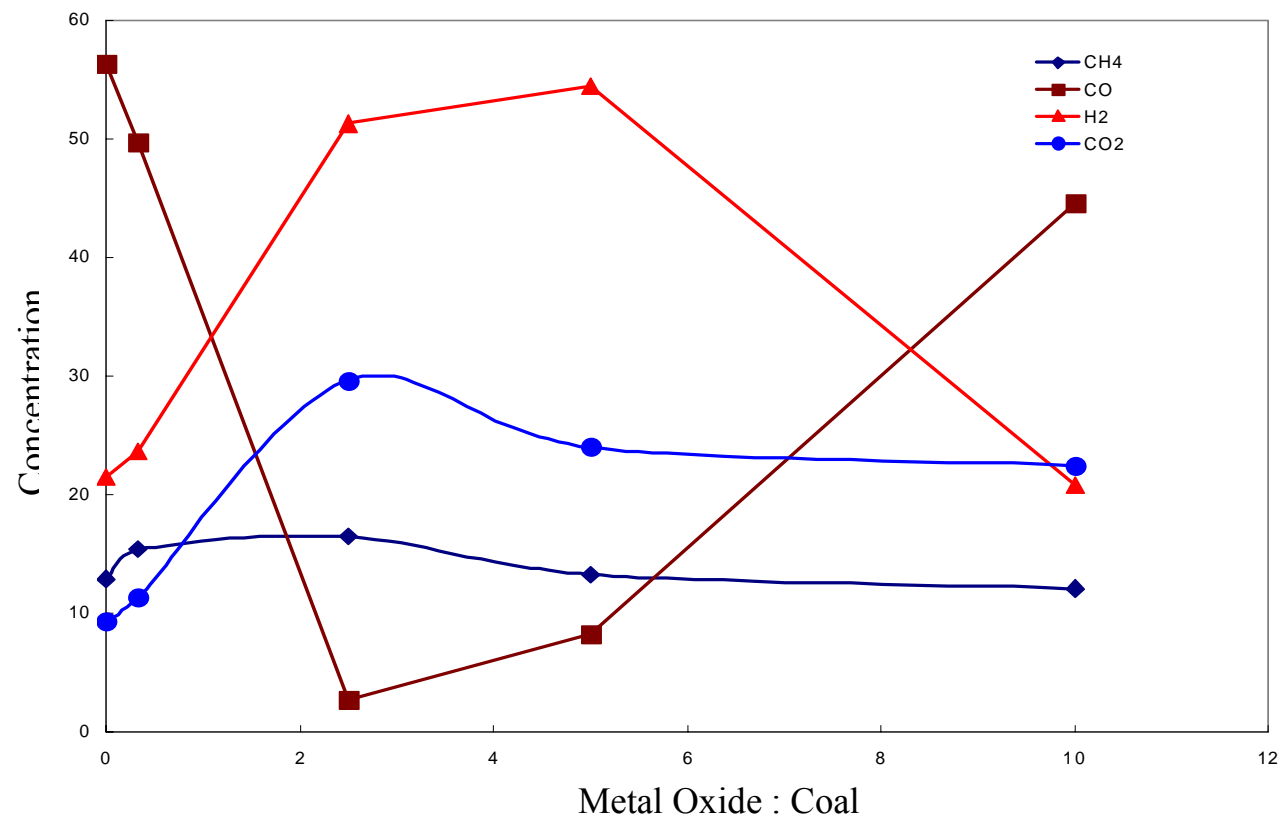

Figure 3-3 Product gas composition Vs OTM/coal ratios.

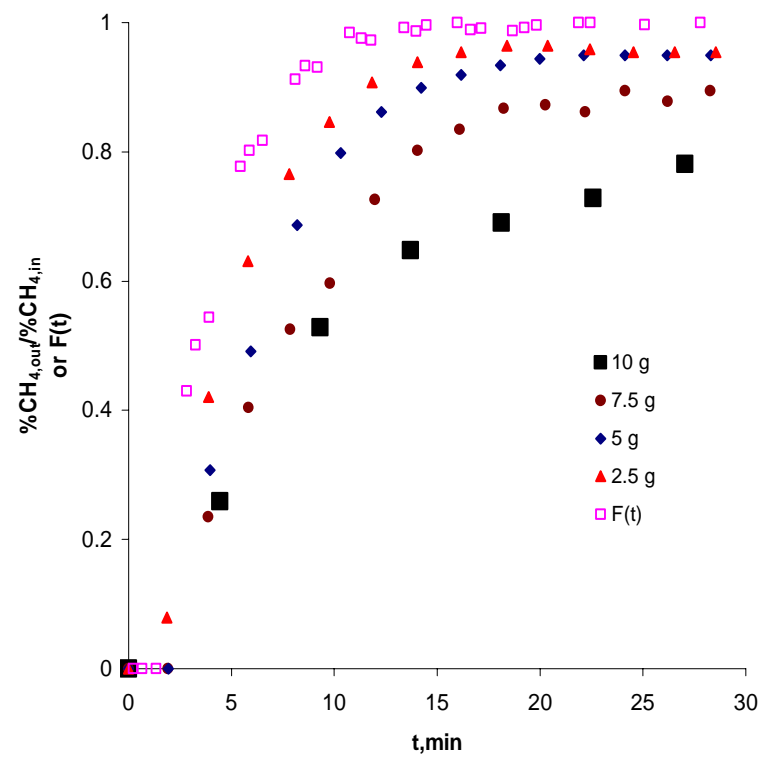

Figure 3-4 Test results - outlet methane Vs OTM loadings. 
Experiments were conducted to assess the reduction of different loadings of OTM during the coal devolatilization stage of coal gasification. This was measured as the extent of reaction of $\mathrm{CH}_{4}$, a key coal volatilization product. Test results are provided in Figure 3-4, which shows the ratio of $\mathrm{CH}_{4}$ exiting to $\mathrm{CH}_{4}$ fed over time. A blank test was run with no OTM, and is shown in Figure 3-4 as $\mathrm{F}(\mathrm{t})$. Other tests were conducted with different OTM loadings. The amount of $\mathrm{CH}_{4}$ that did not react was measured; a value of 1.0 means that $\mathrm{CH}_{4 \text { out }}=\mathrm{CH}_{4 \text { in }}$ : none of the $\mathrm{CH}_{4}$ reacted. Smaller values on the y-axis correspond to greater $\mathrm{CH}_{4}$ consumption.

The different OTM loadings had a significant effect on $\mathrm{CH}_{4}$ reactivity. The trend shown in Figure 3-4 indicates that increasing amounts of OTM lead to increased $\mathrm{CH}_{4}$ reactions. This conclusion was confirmed by the measurement of $\mathrm{CO}_{2}, \mathrm{H}_{2}$ and $\mathrm{CO}$ exiting the reactor, which showed noticeable increases with each step change in OTM loading. Thus, it is important to ensure that sufficient excess OTM is present to react with the coal devolatilization products to minimize $\mathrm{CH}_{4}$ slip from the first reactor.

The impact of temperature is illustrated in Figure 3-5, which shows unreacted $\mathrm{CH}_{4}$ at 700 and $800^{\circ} \mathrm{C}$. The profiles are similar, particularly at longer times, but at $800^{\circ} \mathrm{C}$, more $\mathrm{CH}_{4}$ is consumed early in the test. In addition to these results, measurement of the hydrogen exiting the reactor showed that $\mathrm{H}_{2}$ production was

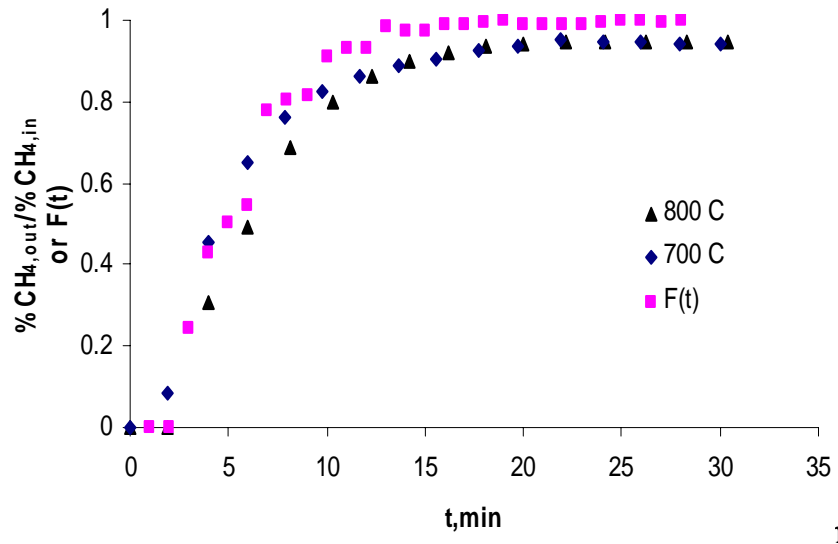
nearly doubled at $800^{\circ} \mathrm{C}$ relative to nption. $700^{\circ} \mathrm{C}$. This further indicates the impact of temperature on the OTM reduction reaction. These data will be used to evaluate the kinetics of the OTM reduction process to ensure that the system is operated at temperatures and residence times that would minimize $\mathrm{CH}_{4}$ slip from the first reactor by promoting sufficient reduction of the OTM.

Detailed thermodynamic analyses were conducted to further characterize the relationship between OTM content and OTM reducing reactions. The amount of oxidized-state OTM present had a significant impact on the amount of $\mathrm{CO}_{2}$ formed. In the UMC system, the preferred product of the first reactor is $\mathrm{CO}_{2}$ rich stream. Thermodynamic analysis findings suggest that this product composition is most likely when there is excess OTM present. Results of tests conducted helped to specify pilot-scale operating conditions as well as derive relevant kinetic parameters. 


\subsection{Pilot Scale Results}

\subsubsection{Shakedown testing of pilot scale system}

During this task, various components of the pilot scale system were tested independently and necessary upgrades were performed as needed.

- Process air shakedown:

Air compressor and a booster were used to provide the high-pressure air required during the pilot plant operation. The compressor and the booster were serviced and leak checked by the vendor and the combined system was tested successfully at 500 psig. The air compressor is shown in the Figure 3-6.

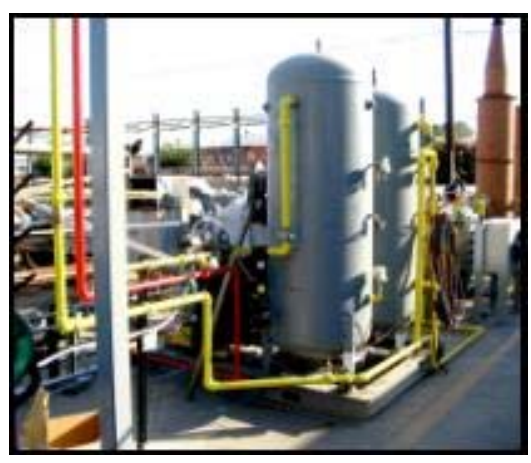

Figure 3-6 Process air shakedown.

- Process steam shakedown:

The boiler and the superheater were successfully tested for 3 hours at 300 psig with superheated steam temperature of $535^{\circ} \mathrm{C}$ prior to conducting tests.

- Cold shakedown of the reactors:

The reactors were pressurized and leak tested at 300 psig. The reactors were filled with OTM and the solid circulation was visually validated at room temperature and ambient pressure with top flanges open. The operating parameters such as optimum pressure drop across the fluidized bed were determined by inspecting the fluidization quality as a function of gas flow rate.

- Shakedown of the scrubber:

The scrubber system used for removing sulfur from the flue gas was successfully tested. Problems with the steady circulation of the scrubber solution were resolved by fixing the recirculation pump and by cleaning the solution injector. $\mathrm{NaOH}$ solution was circulated through the scrubber and $\mathrm{pH}$ was maintained at 11.

- Flare shakedown 
A flare is used to oxidize the unburned hydrocarbons, $\mathrm{CO}$ and $\mathrm{H}_{2}$ in the flue gas. Flare was tested at the firing rate of 250,000 BTU/hr.

- Shakedown of the sampling system

The sampling gas system was validated for dryness and proper minimum flow rates by running process air.

- Control system shakedown

Process control system (instrumentation including thermocouples, pressure transducers, flow-meters \& Labview software) was validated at room temp and ambient pressure. The flow meters, thermocouples and pressure transducers were calibrated. Figure 3-7 shows the screenshot of the Labview control system.

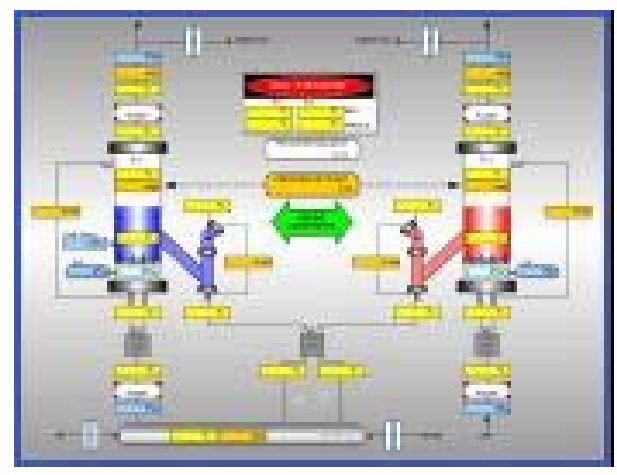

Figure 3-7 Labview control system.

- Safety system shakedown

The shakedown of the independent safety system was completed. The independent system (not dependent on the Labview control system and the computer) isolates the control room at first stage of alert by shutting down all the sampling control valves and turning on the exhaust fan. The $2^{\text {nd }}$ stage alert shut downs the process by turning off the feed valves, boiler, superheater, electric furnaces and process air.

\subsubsection{Operation of the pilot plant}

The second reactor was kept off-line because of potential failure in the distributor plate. Results were obtained by cycling one reactor through combustion and regeneration modes. 
The reactors were preheated to typically $>800^{\circ} \mathrm{C}$ before introducing steam and coal. The preheating was achieved by first flowing high temperature air through the fluidized bed reactors and then adding propane to raise the temperature further. Figure 3-8 shows the typical temperature profile in the fluidized bed during the preheating of the reactor. The electric furnaces installed at the entrance of each reactor typically provided an air stream at $750^{\circ} \mathrm{C}$. The fluidized bed temperature was raised to $\sim 550^{\circ} \mathrm{C}$ from room temperature using this high temperature air. The bed temperature was further raised to $>800^{\circ} \mathrm{C}$ by introducing propane in the reactor along with the fluidizing air as shown in Figure 3-8.

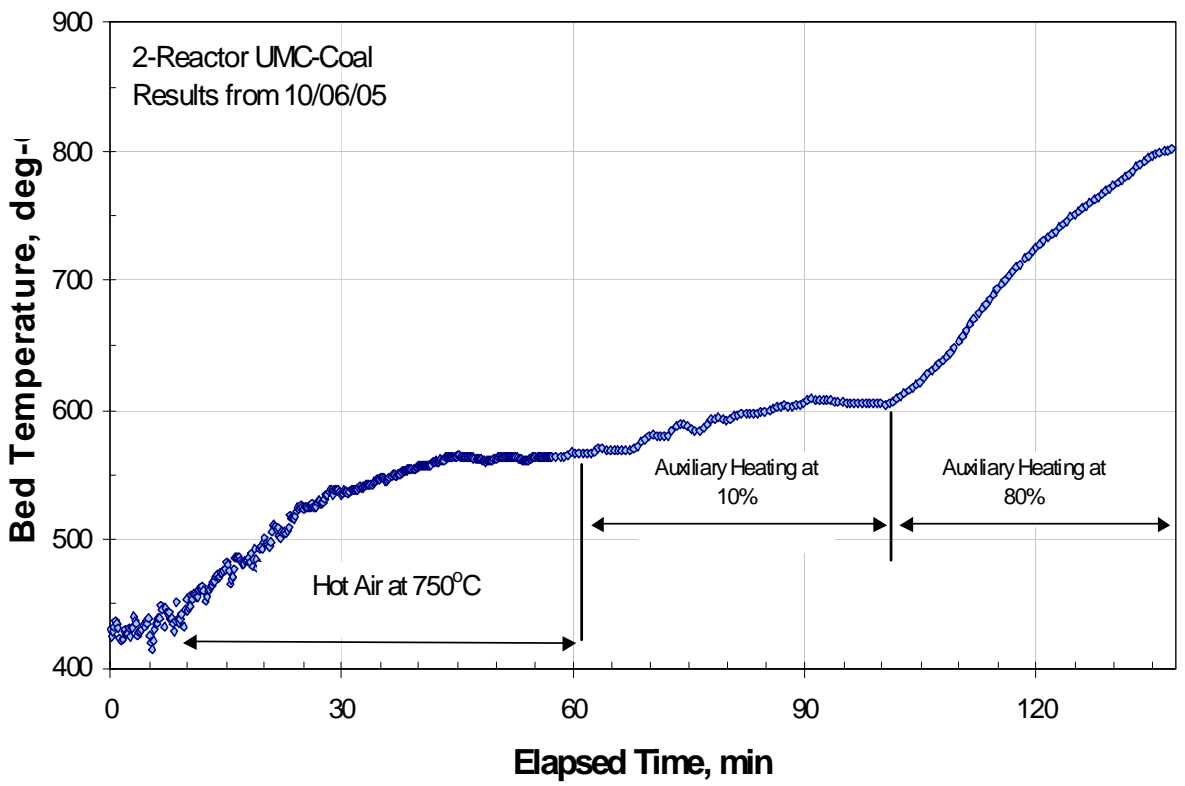

Figure 3-8 Auxiliary pre-heating of reactor.

The unmixed combustion reaction was started after the fluidized bed was preheated and maintained at $\sim 800^{\circ} \mathrm{C}$ for $\sim 2-3$ hours. Reactor 1 was cycled between the gasification/combustion stage and the oxidation stage. The temperature profile during one cycle is shown in Figure 3-9. Initially the reactor was preheated to $800^{\circ} \mathrm{C}$ by introducing auxiliary propane at two locations as shown in the schematic in Figure 3-9. After the reactor temperature was maintained at $800^{\circ} \mathrm{C}$ for $\sim 2$ hours, the fluidizing flow was switched from air to steam to simulate operation of reactor 1 in the UMC-2Reactor process. During steam feeding and the gasification/regeneration cycle the auxiliary propane heating was turned off in order to avoid the mixing of propane combustion products with the gasification/combustion products. The fluidized bed temperature dropped to $\sim 725^{\circ} \mathrm{C}$ in the absence of auxiliary propane heating. Coal slurry $(\sim 45 \%$ coal by weight in water) was introduced after the fluidizing steam flow was stabilized at a 
flow rate of $48 \mathrm{lbs} / \mathrm{hr}$. During this process the reactor temperature dropped quickly and remained stable $\sim 670^{\circ} \mathrm{C}$. This drop in the temperature is mainly from the following reactions occurring in the reactor:

- Endothermic steam gasification of coal to produce $\mathrm{CO}$ and $\mathrm{H}_{2}$

- Reduction of OTM material with $\mathrm{CO}$ and $\mathrm{H}_{2}$ to produce $\mathrm{CO}_{2}$ and steam

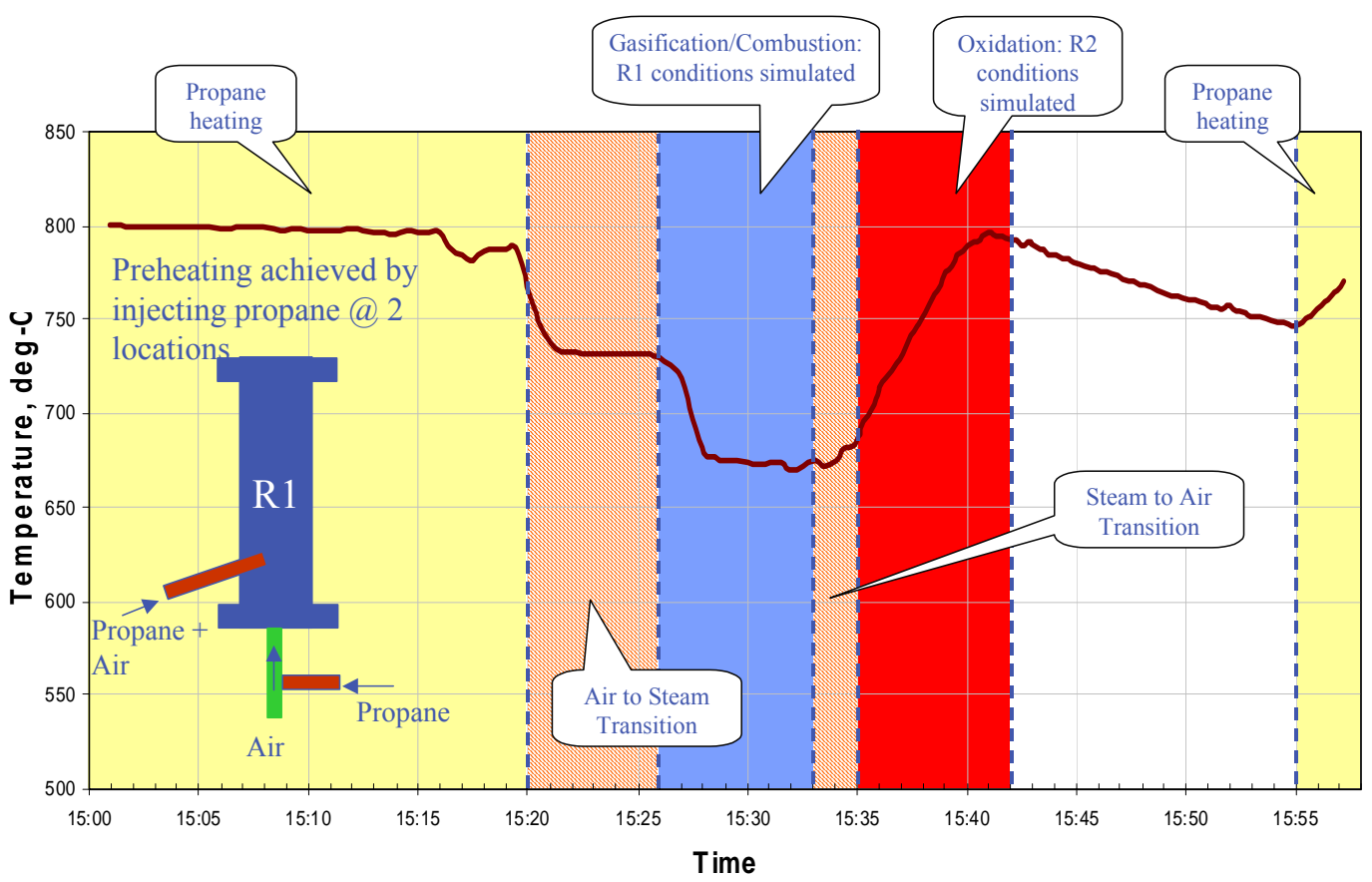

Figure 3-9 Typical temperature profile of $\mathrm{R} 1$ cycling in gasification and oxidation modes.

The quick drop in the temperature followed by the relatively stable temperature profile indicated that the active part of OTM material was reduced completely during the drop in the temperature. During the simultaneous operation there would be a constant supply of fresh OTM coming from the second reactor and the reactor temperature would be maintained steady.

The coal slurry and steam flow was stopped after 5 min and the fluidizing flow was switched to air in order to simulate the operating conditions in reactor 2 . The temperature in the fluidized bed was increased from $670^{\circ} \mathrm{C}$ to $800^{\circ} \mathrm{C}$ when the air was introduced in the reactor. The rise in the temperature is caused by the exothermic reaction, oxidation of the reduced OTM. The reactor temperature started dropping slowly after the initial increase because the OTM was fully oxidized and additional airflow cooled the fluidized 
bed. In the simultaneous operation of the two reactors there would be a constant supply of reduced OTM coming from reactor 1 .

Figure 3-10 shows the temperature and concentration profiles (dry and $\mathrm{N}_{2}$ free) during the simulated operation of reactor 1 in the same experiment. Coal slurry and steam were introduced in the fluidized bed containing OTM which was a metal oxide $\mathrm{MO}_{\mathrm{x}}$. During the initial 2 min period of the coal feeding $\mathrm{CO}_{2}$ was the major detectable product diluted by the lingering air from the preheating mode. $\mathrm{CO}_{2}$ was produced from coal via the following main reactions

$$
\begin{array}{ll}
- & \text { Coal }+\mathrm{H}_{2} \mathrm{O}=\mathrm{CO}+\mathrm{H}_{2} \\
- & \mathrm{CO}+\mathrm{MO}_{\mathrm{x}}=\mathrm{CO}_{2}+\mathrm{MO}_{\mathrm{x}-1} \\
- & \mathrm{H}_{2}+\mathrm{MO}_{\mathrm{x}}=\mathrm{H}_{2} \mathrm{O}+\mathrm{MO}_{\mathrm{x}-1}
\end{array}
$$

Coal reacted with steam to produce $\mathrm{CO}$ and $\mathrm{H}_{2}$ in the endothermic steam gasification reaction. These gasification products further reacted with the oxidized OTM to produce $\mathrm{CO}_{2}$ and steam. Thus during this period the typical conditions in the reactor 1 were simulated and validated.

During the simultaneous operation of the two reactors fresh OTM material would be supplied continuously from reactor 2 and the reactor 1 would produce $\mathrm{CO}_{2}$ continuously. However, during the semi-batch operation mode described in the report, $\mathrm{H}_{2}$ and $\mathrm{CH}_{4}$ were the major products $3 \mathrm{~min}$ after the coal slurry feeding was started. Most likely during this time the active part of OTM was already reduced. Hydrogen was produced from steam gasification of coal and $\mathrm{CH}_{4}$ was produced from coal devolatlization. 
R1 - Gasification Concentrations (balance 02, dry \& N2-free basis)

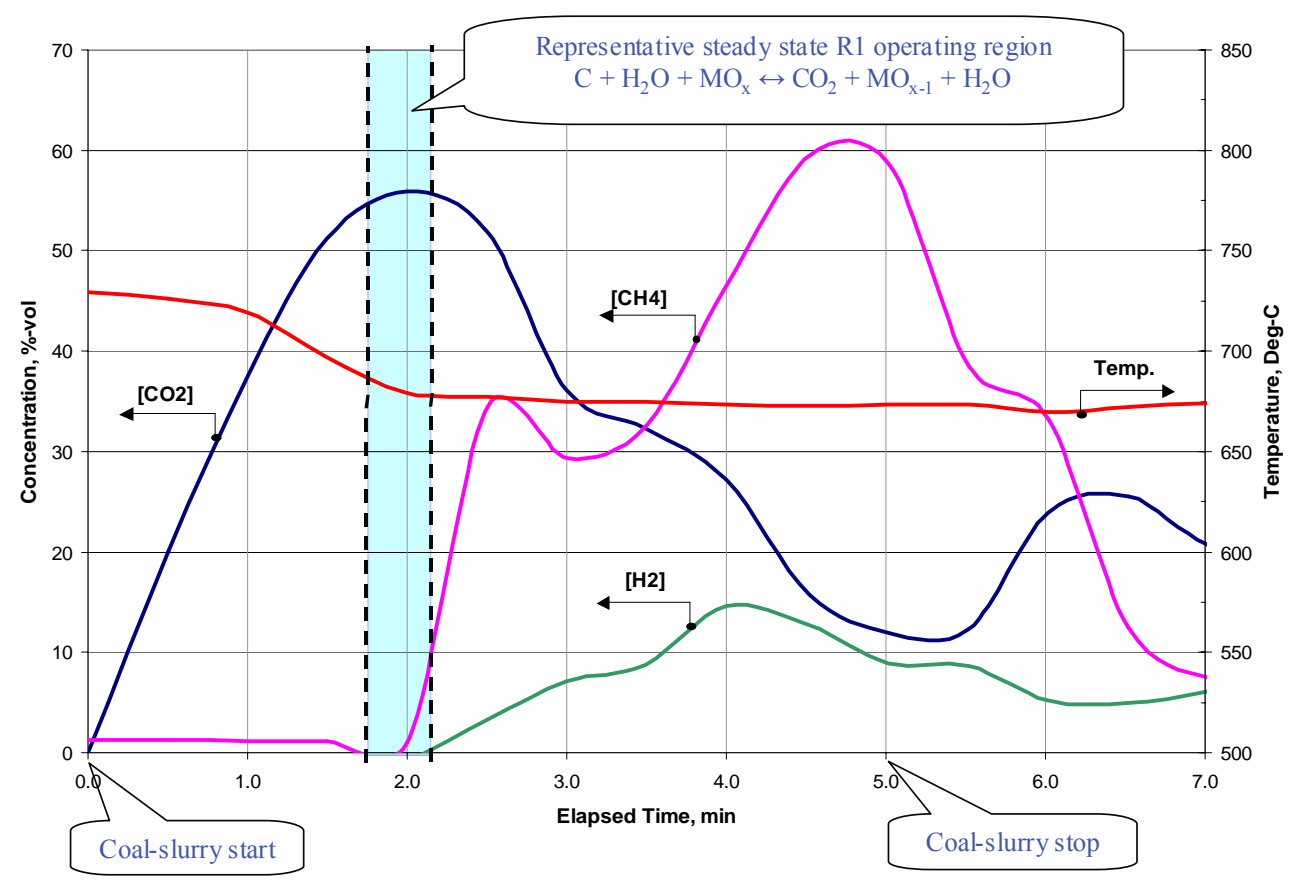

Figure 3-10 Concentration and temperature profile for Reactor 1 simulated operation.

Figure 3-11 shows the concentration and temperature profile during the reactor 2 simulated operation. After simulating reactor 1 operation the coal slurry flow was stopped and the fluidizing gas was switched from steam to air. Oxygen from air was consumed by the OTM in this process and no $\mathrm{O}_{2}$ was detected in the product stream for first $7 \mathrm{~min}$. During this period the temperature of the bed was increased from $700^{\circ} \mathrm{C}$ to $800^{\circ} \mathrm{C}$. The rise in the temperature and the consumption of $\mathrm{O}_{2}$ from the air can be explained by the following exothermic reaction:

$$
\text { - } \mathrm{O}_{2}+\mathrm{MO}_{\mathrm{x}-1}=\mathrm{MO}_{\mathrm{x}}
$$

Oxygen was detected in the reactor products $\sim 7 \mathrm{~min}$ after the air was introduced in the reactor. The rise in the $\mathrm{O}_{2}$ concentration and the corresponding decrease in the bed temperature suggested complete oxidation of the OTM material in the fluidized bed. During simultaneous operation of the two reactors a continuous supply of reduced bed material and this would result in a steady $\mathrm{O}_{2}$ consumption and constant temperature in reactor 2 . 


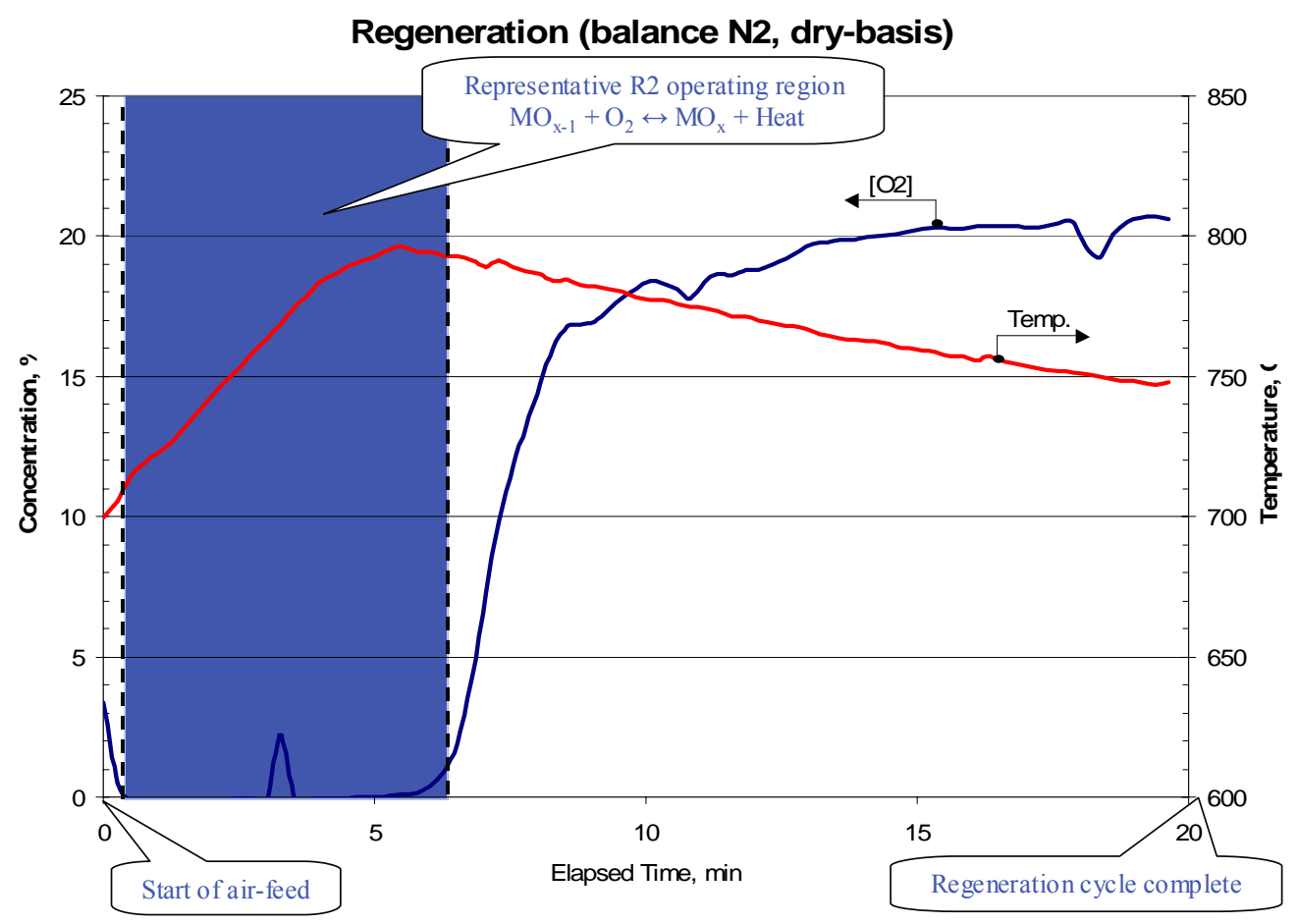

Figure 3-11 Concentration and temperature profile for Reactor 2 simulated operation.

Thus operating one reactor in the gasification/combustion and air regeneration mode validated the basic chemistry of both the reactors in the UMC process in a pilot-scale system. Currently the second reactor is being repaired and upgraded. Simultaneous operation in a two-reactor mode is planned to be conducted under future efforts of this program or spin-off UMC-Coal programs, such as the coal to $\mathrm{H}_{2}$ and electricity project (DE-FC26-00FT40974, Phase II).

\subsubsection{Challenges faced during operation \& recommendations}

During this program the team was able to validate the chemistry of the UMC-2Reactor process by cycling the conditions in one reactor. Limited simultaneous operation of the 2 reactors was carried out at room temperature to validate the solid circulation between the reactors. The challenges faced during the operational phase and suggestions for future work are discussed in this section.

During the current program the pilot plant facility had to be transferred from Irvine, CA to a new test site location in Santa Ana, CA. This was an unplanned move for the program. Transferring and installing the equipment to the new site, updating the required 
AQMD and city permits; getting utilities (electricity, air and water) to the new facility took over 8 months. Even though the team worked on modeling and design tasks during this period, the move to the new facility impacted this 24-month program significantly. The assembly of the pilot plant was completed at the end of the second quarter of 2005 and after that the team was able to carry out shakedown testing and limited experiments. It should be noted that the pilot plant facility was operated for extended periods for the first time during this program. During this period the team obtained valuable operational experience, learned about the limitations of the current design and identified upgrades required in the pilot plant. This experience was very valuable for the future evaluation and development of the UMC technology.

During the operation the team faced issues related to reliability of the peripheral equipment such as the compressor, boiler and coal slurry pump. The air compressor and the boiler had to be repaired and serviced by the vendors frequently. The coal slurry pump was not able to deliver the required minimum slurry feed rate. Also the coal slurry feed line got plugged frequently during testing. This equipment needs to be upgraded or redesigned to meet the requirements of the next program.

The reactor auxiliary pre-heating system of injecting propane into the fluidizing air in the current design also has limitations. To get reliable auto ignition of the propane/air mixture, the air in the reactor needs to be preheated to $>500^{\circ} \mathrm{C}$. During the testing, propane was injected in two locations: 1) directly in the fluidized bed and 2) pre-mixed with heated air. The required pre-heating temperature of $800^{\circ} \mathrm{C}$ was obtained by following a systematic procedure of injecting proper amounts of propane in the reactor. However, this design does not provide auxiliary heating during coal slurry feeding with steam as the fluidization gas. Auxiliary heating is required in the coal slurry feeding for the pilot-scale coal combustion unit because of the heat loss from the system due to its experimental size. The auxiliary heating is not required for commercial scale systems. A robust auxiliary heating system capable of providing heating during both pre-heating and reaction modes needs to be designed for future experiments on UMC technology.

During the operation of a single reactor in the semi-batch mode, agglomeration of some OTM particles was observed at reactor temperature of $\sim 700^{\circ} \mathrm{C}$. Further analysis indicated that the agglomerates were formed because of melting of the alkali metals in the ash. This ash was accumulated during the feeding of coal slurry in the reactor. An ash removal strategy needs to be developed for the pilot plant design. The ash removal strategy may include investigating various approaches including coal washing, entrainment of ash particles and methods for separating ash from solids.

The current pilot-scale reactor design also needs to be modified. The distributor plate at the bottom of the reactor plugged frequently during the operation. The design of the distributor plate needs to be modified. 
GRC is currently investigating another technology based on unmixed combustion called UMC-3Reactor technology (DE-FC26-00FT40974, Phase II) that can potentially produce 3 separate streams of hydrogen, $\mathrm{CO}_{2}$ and high temperature pressure vitiated air to produce electricity in a gas turbine expander under another DOE funded project. The lessons learned during the current project will be implemented in the investigation of UMC-3Reactor technology. 


\section{PROCESS MODELING \& ECONOMIC ANALYSIS}

\subsection{Global process modeling}

\subsubsection{Process modeling}

The objectives of the process modeling task were to develop models for the UMC-Coal technology, validate them using experimental data, and apply the models to assist in the design and operation of the pilot-scale system.

\section{Selection of Process Modeling Tool}

Choosing an appropriate process modeling tool and using proper model assumptions are the most important items in estimating the performance and efficiency of the UMC-Coal to electricity processes. The initial process modeling efforts were accomplished using simple process assumptions and excel-based modeling tools. The excel-based modeling tools have some limitations such as requirement of rigorous subroutines to simulate reactions. Also, excel-based models require more time to create new sub-model and also to make changes in the existing model. To choose the right tool, a GE Six Sigma project was completed where different options were weighed against performance targets for process modeling of advanced power generation processes. Figure 4-1 shows the process map for selecting the best process model tool. The high level customer requirement (accurate estimation of efficiency) was flowed down to quantifiable process modeling characteristics such as ability to perform equilibrium calculations, time required for creating a new process model, etc. The process modeling options were compared against these characteristics. Based on this analysis ASPEN Plus was chosen as the best process modeling tool. Further a combination of Aspen (chemistry) and GateCycle (power island) model was used to improve the efficiency estimates.

The process modeling assumptions were finalized based on extensive discussions and input from gasification and combined cycle plant experts from U.S. DOE and GE Energy. 


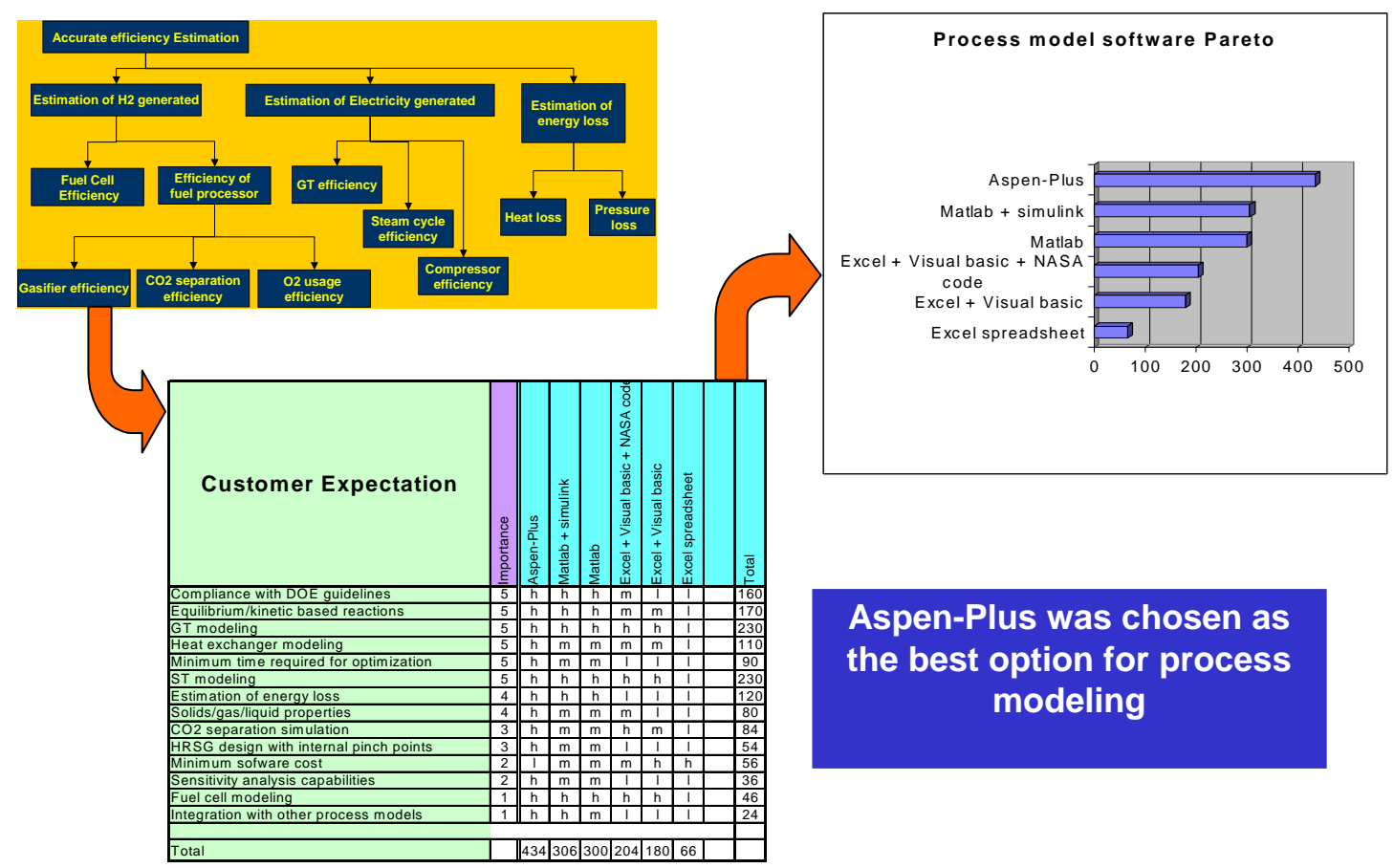

Figure 4-1 Selection of the best process modeling tool

\section{ASPEN Plus Based Process Modeling}

The process modeling of the UMC-Coal technology was performed using ASPEN Plus version 11.1. ASPEN Plus (Aspen Technology, Inc.) is engineering software that can perform process analysis for various unit operations (including reactions, separations, drying, etc.) and process design calculations for heat exchangers, pumps and turbines. ASPEN Plus can also handle steady state processes involving solids such as coal. Some of the solids processing applications that have been modeled with Aspen Plus include:

- The Bayer process

- Cement kilns

- Coal gasification

- Hazardous waste incineration

- Iron ore reduction

- Zinc smelting/roasting

These capabilities make ASPEN Plus an ideal process analysis tool for the UMC technology, which includes chemical processes involving solids such as coal, and oxygen transfer material (OTM). 
The process flow diagram (PFD) of the UMC-Coal concept was constructed in ASPEN Plus. Figure 4-2 shows a simplified version of the UMC-Coal system integrated with the combined cycle plant. The first reactor acts as an unmixed combustor and produces $\mathrm{CO}_{2-}$ rich stream at high pressure $(30 \mathrm{~atm})$. The heat required for the combustion is primarily supplied by the OTM flowing into the unmixed combustor ( $1^{\text {st }}$ reactor) from the oxidizer ( $2^{\text {nd }}$ reactor). The $\mathrm{CO}_{2}$ produced can be recycled in the first reactor to assist the fluidization. Using $\mathrm{CO}_{2}$ for fluidization reduces the steam requirement and results in higher efficiency. The $2^{\text {nd }}$ reactor oxidizes the reduced OTM coming from the $1^{\text {st }}$ reactor and produces vitiated air at high temperature and pressure. The product of the $1^{\text {st }}$ reactor is sent to a heat recovery system, a shift reactor to convert remaining $\mathrm{CO}$ to $\mathrm{CO}_{2}$, a gasclean-up system and finally to a $\mathrm{CO}_{2}$ separation device such as a condenser. The product of the second reactor is sent to a gas turbine and a heat recovery steam generator (HRSG) unit. Figure 4-3 shows the process flow diagram for the entire steam cycle including the HRSG and steam turbines. The process model for the UMC-Coal process and the combined cycle plant follows DOE guidelines for process modeling.

Major Process Analysis Assumptions

- The two reactors (unmixed combustor and oxidizer) were assumed to be thermodynamically limited at steady state (Gibbs reactors).

- The maximum temperature of the oxygen transfer material was limited to $1275^{\circ} \mathrm{C}$ at steady state.

- The maximum metal temperature in the heat exchangers was limited to $650^{\circ} \mathrm{C}$.

- The process was conducted at $30 \mathrm{~atm}$ pressure.

- Simulated Gas Turbine: (LM 6000 SPT). Simulation with 3-stage expansion and cooling air.

- Three pressure reheat steam cycle with high, intermediate and low pressure steam turbines

- Steam generated at $1800,500,300,42$ and $17 \mathrm{psi}$

- Internal pinch point $15^{\circ} \mathrm{C}$

- Introduction of mechanical and auxiliary losses (in compressors, turbines, control systems etc.)

- Mechanical losses in ST Generator: $1.5 \%$

- Mechanical and generator losses in GT Generator: $2.5 \%$

- Auxiliary losses: $2 \%$

- Stack gas temperature: $100^{\circ} \mathrm{C}$

- The $\mathrm{CO}_{2}$ stream was compressed to $2100 \mathrm{psi}$ (sequestration-ready pressure)

- The process analysis was carried out for Illinois \#6 Old Ben \#26 Mine coal (HHV $11,666 \mathrm{Btu} / \mathrm{lb})$. 


\section{GE -UMC CYCLE}

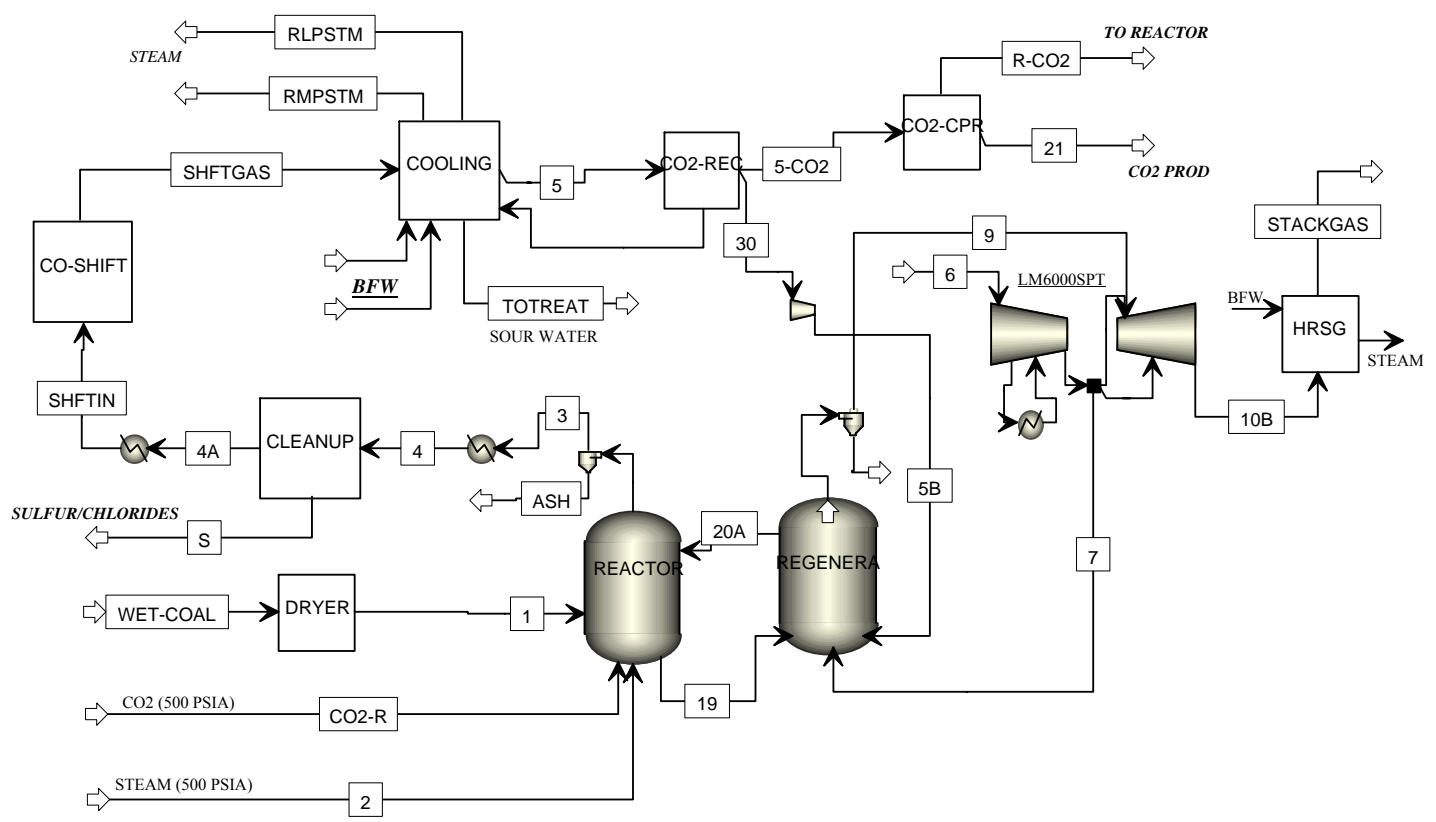

Figure 4-2 Simplified process diagram of UMC-Coal to electricity 


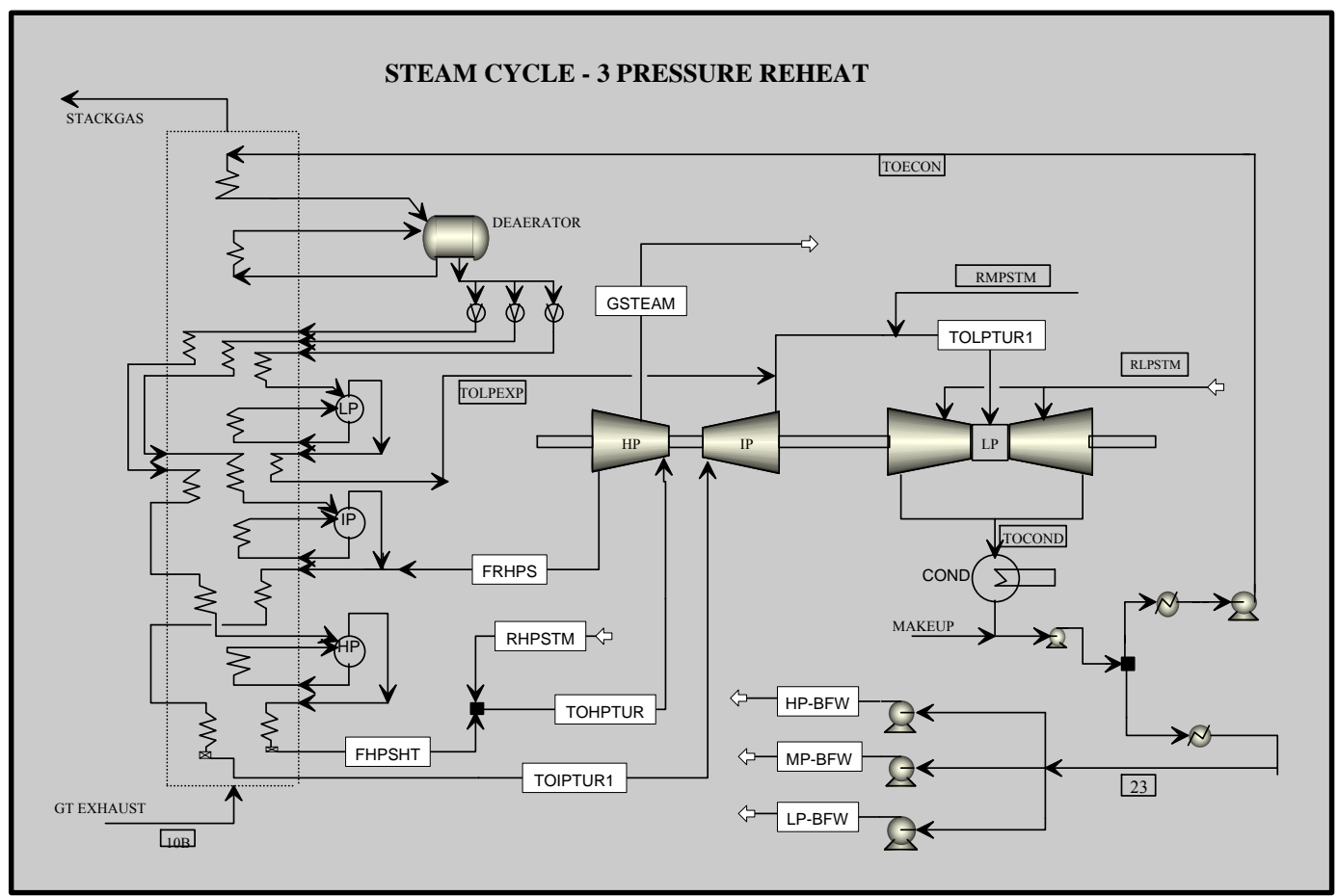

Figure 4-3 Process flow diagram for the 3-pressure reheat steam cycle

\subsubsection{UMC-Coal efficiency estimates and comparison with IGCC}

The efficiency of the process configuration was estimated based on the results of a Process flow diagram for the 3-pressure reheat steam cycle obtained using the ASPEN Plus simulations.

The process efficiency of the UMC-Coal system was compared to an IGCC process with $\mathrm{CO}_{2}$ separation in an apples-to-apples comparison. Figure 4-4 shows the simplified Net electricity (MW)

Net Efficiency, $\%=$ HHV of Coal fed (MW) $_{100 \%}$

process flow diagrams for (A) Typical IGCC system with $\mathrm{CO}_{2}$ separation and (B) UMCCoal combined cycle system. To have an apples-to-apples comparison, the process model assumptions were kept identical for both processes. The two reactors in the UMC-Coal 
process were replaced by a gasifier, and an air separation unit (ASU) for the IGCC process simulation.

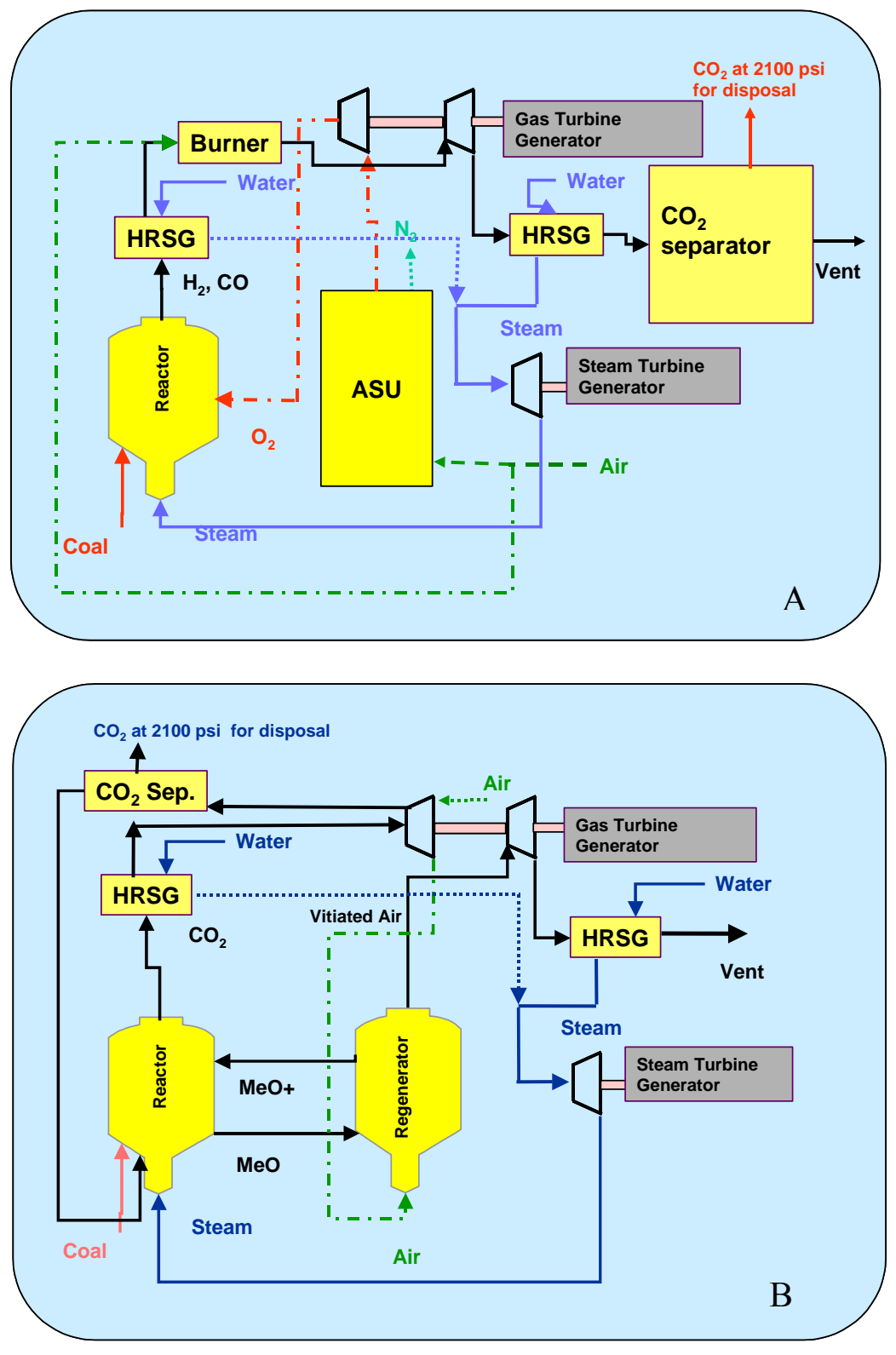

Figure 4-4 Process flow. diagrams

(A) Typical IGCC process with $\mathrm{CO}_{2}$ separation

(B) UMC process integrated with the combined cycle plant. 
GE is currently evaluating the efficiency and cost comparison of UMC \& IGCC technologies internally. Results of the comparison will be shared with DOE under another ongoing UMC-3Reactor technology program.

The overall advantages of the UMC-Coal system over the IGCC process are listed below:

- The UMC-Coal technology does not require the use of an Air Separation Unit (ASU).

- The product of the $2^{\text {nd }}$ reactor in the UMC-Coal process goes directly to the gas turbine without getting cooled; while in the IGCC process the gasifier products need to be cooled down for gas clean up before being sent to the gas turbine. The UMCCoal process thus avoids the energy lost in cooling and reheating the process streams.

\subsection{Process Modeling to Identify Initial Experimental Conditions}

The objective of this task was to develop process models for the pilot scale UMC facility and assist the operation of the pilot-scale system. Prior to the start up of the UMC pilot scale system, the process model was used to help identify the key operation conditions and predict experimental results.

\subsubsection{Pilot scale process description}

As shown in Figure 4-5, Aspen Plus software was used in developing the pilot scale UMC system model. The first reactor acts as an unmixed combustor and produces $\mathrm{CO}_{2}$ rich stream at high pressure. The heat required for the combustion is primarily supplied by the OTM flowing into the unmixed combustor (1st reactor) from the oxidizer (2nd reactor). Due to the high heat loss associated to small-scale reactors, auxiliary heat input (propane combustor) was required. The 2 nd reactor oxidizes the reduced OTM coming from the 1st reactor and produces vitiated air at high temperature and pressure. Superheated steam at $350^{\circ} \mathrm{C}$ was used as both fluidization gas for reactor 1 and as carrier gas for solid transfer between the two reactors. The exhaust gas from the two reactors was sent to thermal oxidizer (flare) and released. 


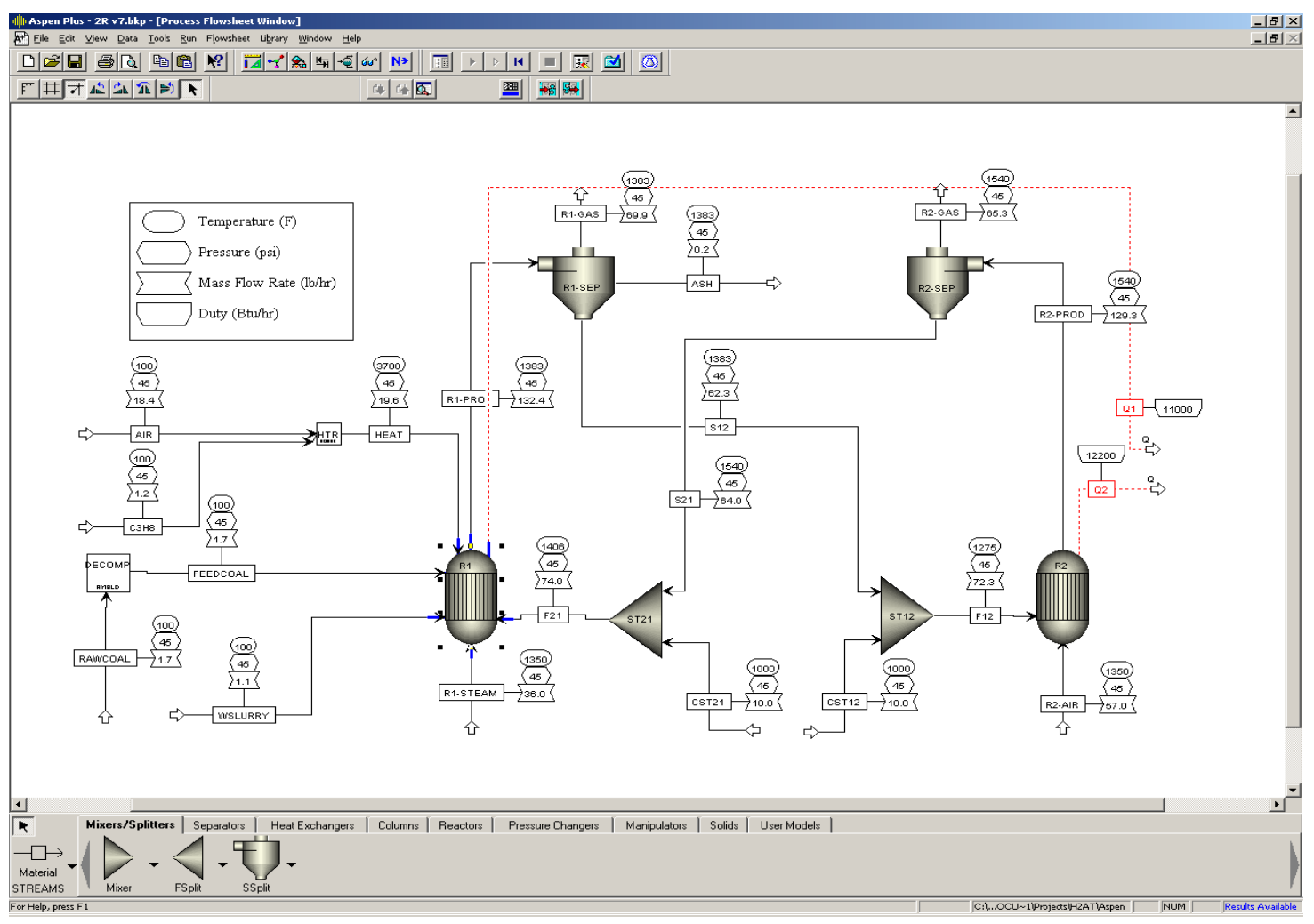

Figure 4-5 UMC pilot scale system model in Aspen

\subsubsection{Major process analysis assumptions}

The following assumptions were made when developing the Aspen process model for UMC pilot scale system:

- The two reactors (unmixed combustor and oxidizer) were assumed to be thermodynamically limited at steady state (Gibbs reactors).

- The maximum temperature of the oxygen transfer material was limited to $1275^{\circ} \mathrm{C}$ at steady state.

- The maximum metal temperature in the heat exchangers was limited to $650^{\circ} \mathrm{C}$.

- The process was operated at $30 \sim 60$ psig pressure.

\subsubsection{UMC pilot scale system modeling results}

As shown in Figure 4-6, major experimental conditions were identified using the pilot scale system model. Including mass flow of fluidization gas into the two reactors, optimal slurry flow rates and solid circulation rates, expected auxiliary heating requirement, 
estimated reactor outlet temperatures, product gas compositions, etc. Based on this information, a test matrix was designed and all associated operation parameter values identified prior to the start of the pilot scale system testing. 


\section{REACTOR-1}

\begin{tabular}{|l|r|l|}
\hline & Mole Frac & \\
\hline $\mathrm{CO} 2$ & $86 \%$ & \\
\hline $\mathrm{CO}$ & $0.50 \%$ & \\
\hline $\mathrm{N} 2$ & $1 \%$ & \\
\hline $\mathrm{H} 2$ & $11 \%$ & \\
\hline $\mathrm{H} 2 \mathrm{~S}$ & 511.9 & $\mathrm{ppm}$ \\
\hline
\end{tabular}

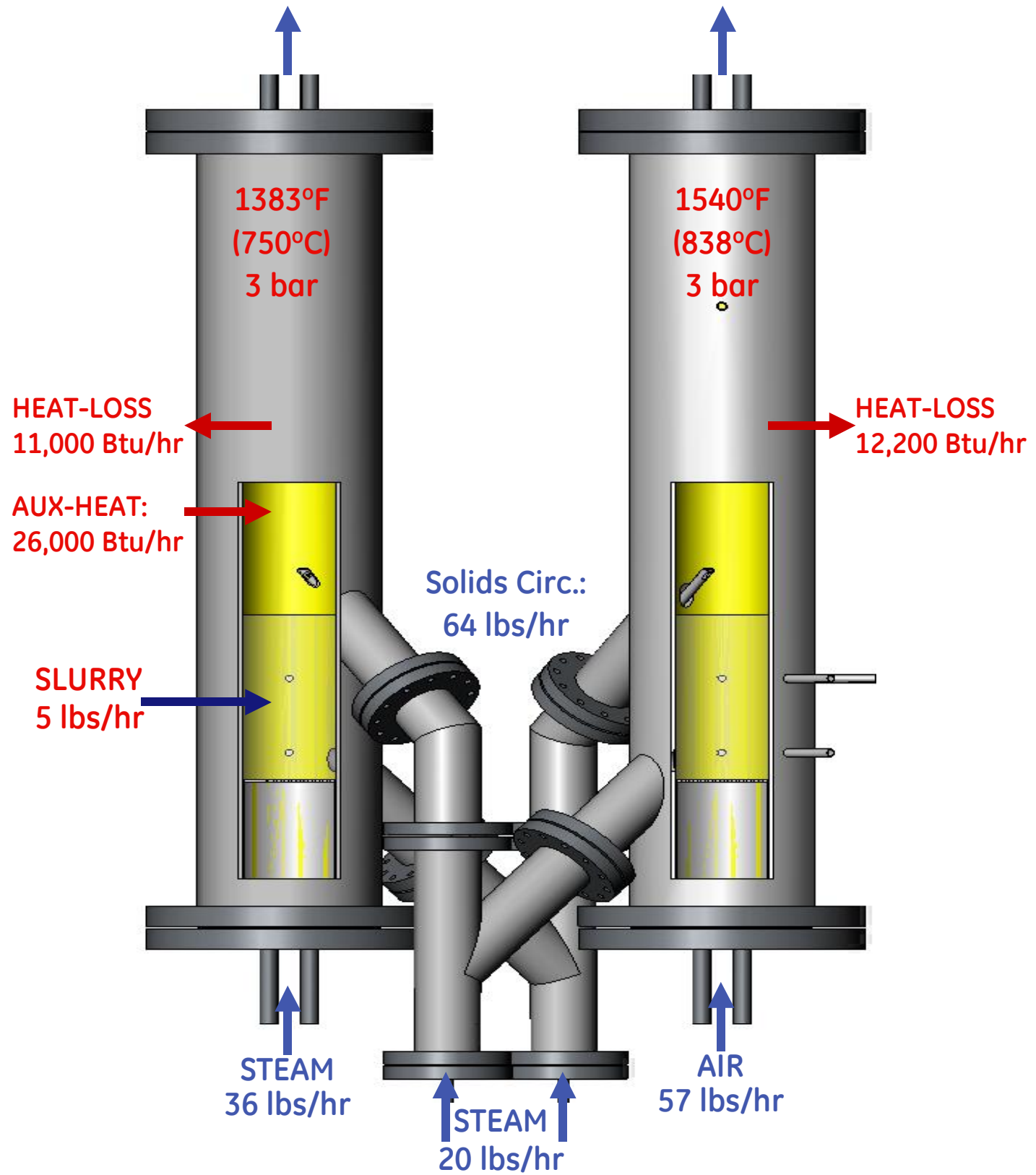

REACTOR-2

\begin{tabular}{|c|c|}
\hline & molar fraction \\
\hline N2 & $81.8 \%$ \\
\hline O2 & $16.3 \%$ \\
\hline NO2 & $3.2 \mathrm{ppm}$ \\
\hline $\mathrm{NO}$ & $83.5 \mathrm{ppm}$ \\
\hline $\mathrm{CO} 2$ & $2.0 \%$ \\
\hline
\end{tabular}




\subsection{Process Design \& Economics of Commercial Scale UMC- 2Reactor System}

The economics of the UMC process are an important aspect of development efforts. GE Global Research is working with Worley Parsons to develop detailed estimates of UMC plant costs to assess the commercialization potential of the technology as well as to guide future development efforts.

Work in this task includes the following sections.

\subsubsection{Commercial scale UMC system modeling}

The development of commercial scale UMC system model is a natural extension of the previous modeling works on the UMC system. Material flow rates were updated to commercial scale and to match existing gas turbines and heat recovery steam generators. This model is combined with a Gate-Cycle model for detailed material and energy balance of the entire power generation system.

\subsubsection{Fluidization calculations and reactor vessel sizing methodology}

Fluidization calculations were performed based on the system mass and energy balances from commercial scale process model. For any given fluidized bed geometry (internal diameter $\mathrm{D}$ and aspect ratio $\mathrm{Lmf} / \mathrm{D}$ ), important data characterizing the fluidization conditions was calculated including the minimum fluidization velocity umf and maximum reactor aspect ratio $(\mathrm{Lmf} / \mathrm{D})$ max, bed void fraction, total reactor height, mass of the bed, solid residence time, superficial gas velocity, etc. By iteratively calculating the fluidization conditions over a series of reactor geometries, a fluidization design map was developed for each reactor, as shown in Figure 4-7. 
Further fluidization calculation was carried out to study the effect of particle sizes on

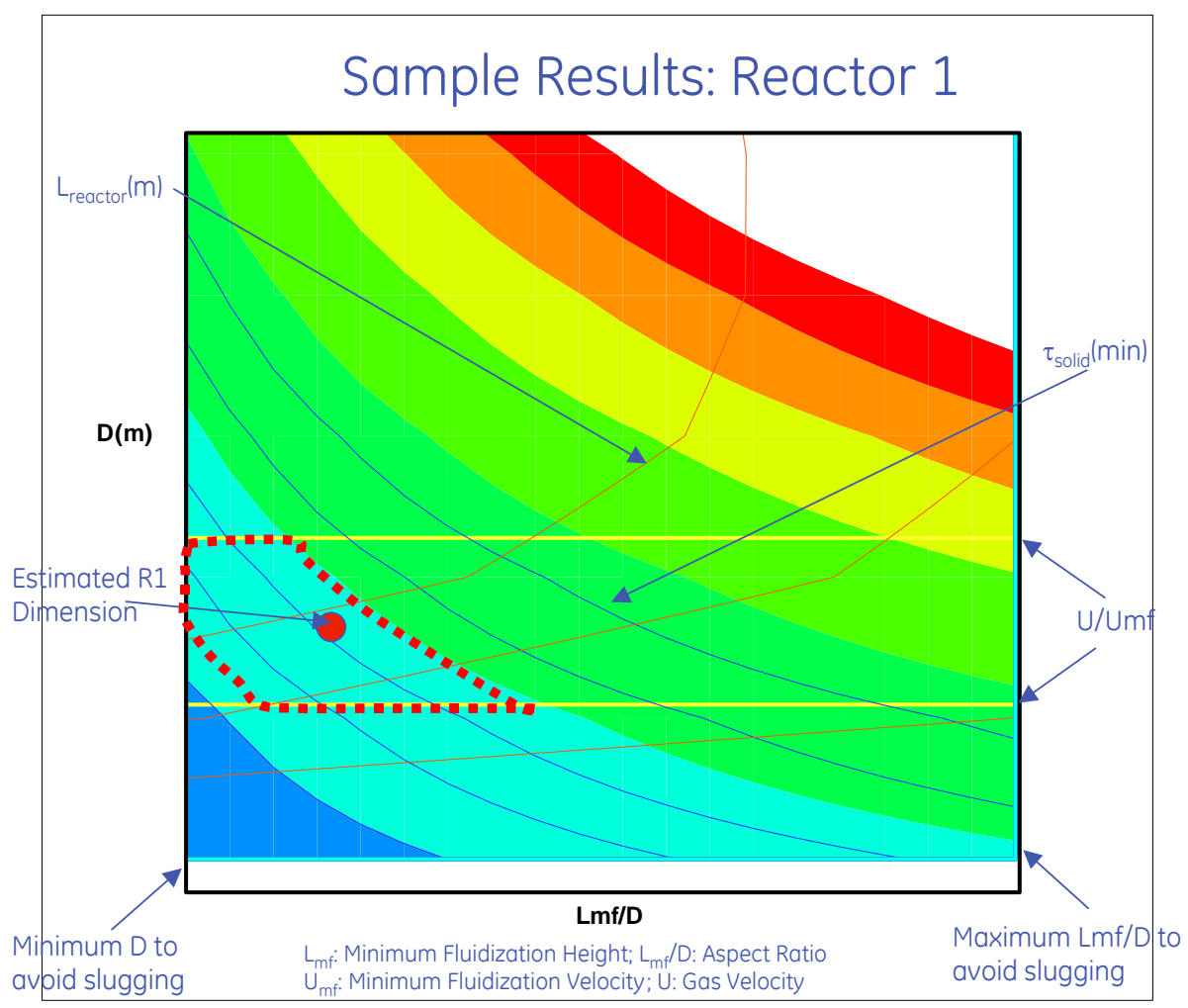

Figure 4-7 Fluidization calculations and reactor sizing.

reactor geometries. Results indicate that the solid particle sizes in UMC system can range from 10 micron to 800 micron. Generally, smaller particles require lower fluidization gas velocity and higher transport disengagement height to prevent particle entrainment. 
Figure 4-8 shows various particle sizes in reactor 1 and their corresponding reactor lengths that are required to prevent particles from being conveyed out of the fluidized bed. As the particle size decreases, the required transport disengagement height increases, resulting in an increase in the total reactor height. After a critical height of reactor, the decrease in particle size would result in much faster increase in the total reactor height and thus a significant increase in the capital cost of the

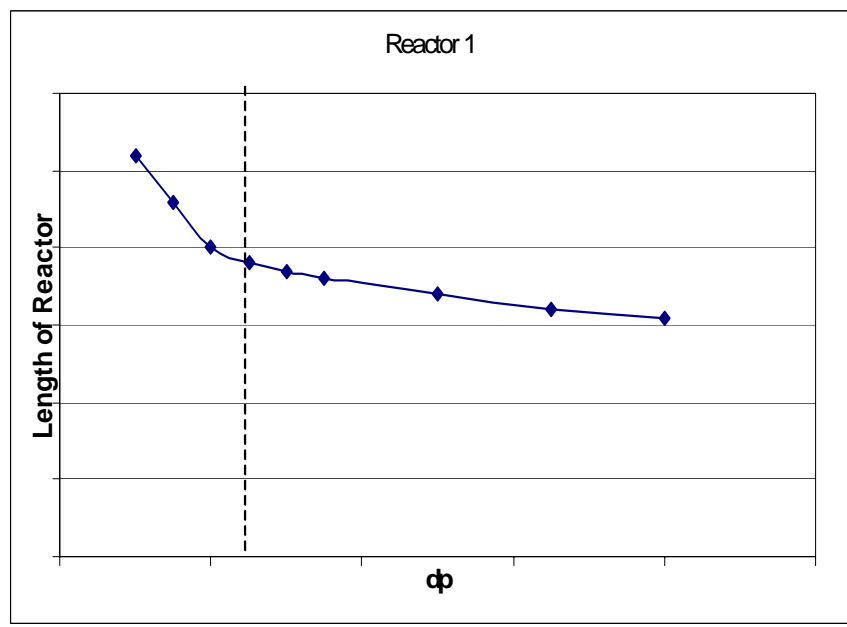

Figure 4-8 Reactor length for different particle sizes. reactor vessel. At this point, the height of the reactor would only allow particles smaller than the critical particle size to escape from the reactor, which can then be collected using a cyclone and re-injected back to the reactor. Therefore, the critical reactor length was chosen as optimal design point any increase in reactor height would become highly inefficient in preventing particle entrainment while any decrease in reactor height would result in significant higher requirement for the cyclone capacity.

\subsubsection{Peripheral equipment estimations}

Once the final reactor dimensions were finalized, more detailed designs were carried out including refractory, reactor vessels, solid transfer ducts and solid separation equipments.

Typical refractory and metal shell materials were selected for the UMC reactors. Pressure vessel shell thickness and reactor heat transfer (Figure 4-9) calculations were performed for each reactor to determine the thickness of each layer of materials to satisfy both the temperature and the pressure requirement of the reactors.

Designs for solid transfer ducts were also conducted. Solid transfer between reactor 1 and reactor 2 can be accomplished using gravity or steam as carrying gas. According to the different

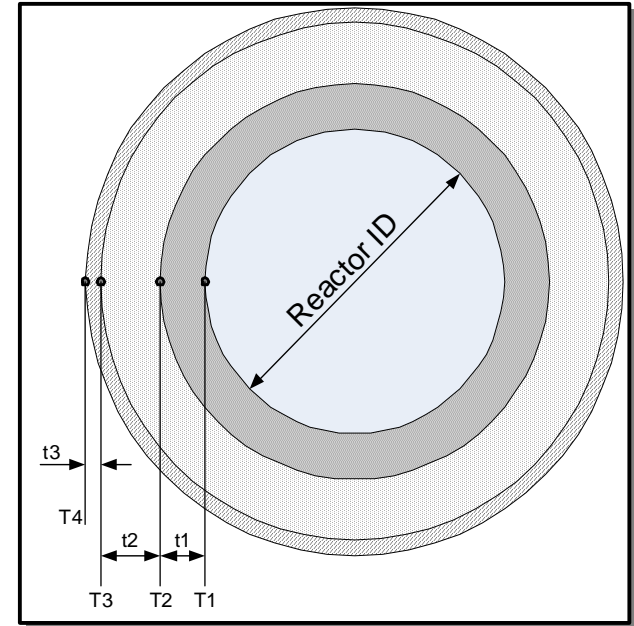

Figure 4-9 Refractory and shell thickness estimation. 
temperature and pressure requirements for each solid transfer ducts, their corresponding refractory and shell materials and thicknesses were also estimated.

Fluidization calculation results also provided information on determining the solid separation equipments for the UMC processes. Gas and entrained solid flow rates were provided to outside vendors specializing in gas/solid separation units to estimate cyclone sizes and costs. Final costs were estimated based on the $1^{\text {st }}$ order process design, equipment sizing and unit cost estimations provided by outside vendors. Worley Parsons will directly use this information for the final economic analysis of the UMC technology. A list of equipment specifications along with the UMC process flow diagram was completed and submitted to Worley Parsons to estimate the capital cost of the system.

\subsubsection{Methodology for COE calculation}

The cost of electricity will be calculated for both IGCC with $\mathrm{CO}_{2}$ separation and UMC technology at commercial scale based on the capital cost information received from Worley Parsons, O\&M cost and the efficiency estimates. DOE's H2A model will be used as a guideline to develop the COE model. The costs will be internally reviewed by GE and then reported to DOE under future efforts of this program or spin-off UMC-Coal programs currently under development. 


\section{CONCLUSIONS}

The current program to investigate the novel UMC-Coal technology has successfully validated the chemistry aspects of the technology in a pilot-scale system. The program objectives were met through lab-scale experimentation, successful reconstruction of a pilot plant, and pilot-scale testing. Although only limited pilot plant testing data was collected because of delays associated with an unplanned move of facilities from Irvine, CA to Santa Ana, CA, the team was able to get important technical data to validate the chemistry associated with the technology. The pilot plant, designed in a previous DOE funded program (DE-FC26-00FT40974), was reconstructed and operated for extended period for the first time. Limitations of the current design and several upgrades required in the design were identified. Global process modeling of the technology was completed and a methodology to compare the cost of the UMC technology with the conventional gasification technology was developed. Although additional work is needed at the pilot scale to further characterize performance and retire risks such as cost, sorbent lifetime and impact of pollutants, the results obtained to date suggest that the UMC technology has the capability to meet the efficiency, environmental and economic goals of both the DOE and industrial customers. The risks associated with the UMC technology are currently being addressed in another DOE funded project ending in September 2007 (DEFC26-00FT40974. Phase II) and therefore GE would be in a better position to make recommendation about the UMC-Coal technology in 2007.

Key accomplishments in each program task are briefly outlined below.

- Task 1 Lab-Scale Experiments - Fundamentals

The subcontractor, SIU, performed lab scale tests by designing experimental fixed bed system capable of operating at high pressure and temperature $\left(300 \mathrm{psi}, 800^{\circ} \mathrm{C}\right)$. Parametric experiments on steam gasification of coal in the presence of OTM were carried out. The operating parameters such as the temperature, steam to carbon ratio and the OTM/coal ratio were validated using this study. To get more quantitative and relevant technical information for the development of UMC technology more robust experimental system capable to handling temperatures $\sim 1200^{\circ} \mathrm{C}$ under high pressure is required. Also, kinetics of various reactions involved in the UMC process need to established using the bench scale experiments. The lessons learned in this program will be implemented in another on-going DOE funded UMC-3Reactor program. 
- Task 2 Global process analysis

Global process analysis of the UMC-Coal process was carried out using Aspen Plus software. An overall mass and energy balance of the entire process was developed based on thermodynamic modeling. This information was used to redesign the pilot-plant and also to identify the operating parameters for the experiments. The global process model was also used to determine the flow rates for a commercial scale UMC system in order to get the cost information. In future the thermodynamic model needs to be validated based on the kinetic information obtained from the pilot-scale and/or the bench scale experiments.

- Task 3 System Design and Engineering

A pilot plant experimental facility designed in a previous DOE funded UMC program (\#DE-FC26-00FT40974) was redesigned for the UMC-Coal process. Several modifications were performed in the existing design in order to make the facility more robust and reliable. The refractory thickness in the reactors was increased to reduce the heat loss; the coal slurry system was modified to minimize plugging. Various designs for solid circulation were considered and validated using cold flow system and the most reliable design was implemented in the pilot scale.

During this program the pilot-scale experimental facility was operated for extended period of time and several limitations of the current designs were identified. The system is currently being upgraded under another UMC-3Reactor DOE program.

- Task 4 System Fabrication, Assembly and Shakedown

The fabrication, assembly and shakedown of the pilot-scale experimental facility was completed at the Santa Ana test site. A safety review was carried out and operating procedure was developed before initiating the experiments. Each unit operation was shaken down separately under the design conditions. The task was delayed by 8 months because of the delays associated with change in the site, updating the required AQMD and city permits and connecting utilities at the new site.

\section{- Task 5 Pilot Plant Operation}

The pilot-scale facility was operated and the chemistry associated with the UMC-Coal process was validated by single reactor cyclic operation. During the gasification/combustion stage $\mathrm{CO}_{2}$ was the major detectable product. During the 
oxidation stage oxygen in the air was consumed by the OTM and high temperature vitiated air was produced.

Several limitations of the current pilot-plant design were identified during the operation especially related to auxiliary heating and coal slurry feeding. Agglomeration of the bed material most likely due to melting of alkali metals in the ash was also observed during the cyclic experiments. Only limited pilot-plant operation was possible because of these limitations. Currently the design is being upgraded under another DOE funded program on UMC technology. The major upgrades needed mainly include a robust auxiliary heating system to maintain required operating temperatures to investigate the technology and removal of ash from the OTM material.

- Task 6 Full-Scale Conceptual Design and Economic Analysis

A methodology was developed to perform economic apples-to-apples comparison of the UMC-Coal process with conventional gasification technologies at a commercial scale. Process models to get the overall material and energy balance were developed using AspenPlus and GateCycle software. Fluidization models were developed to identify the reactor dimensions and number of trains required to generate the required amount of electricity. The flow-rates and reactor sizes were sent to Worley Parsons for capital cost (CAPEX) estimates. Based on the CAPEX estimates the cost of electricity (COE) will be calculated using a model developed on the basis of DOE's H2A model and will be reported in future efforts of UMC-Coal development programs.

- Task 7 Project Management and Technology Transfer

Despite delays in obtaining operating permits and an unexpected relocation of the testing facilities, the project has consistently generated meaningful data and been managed toward validation of the essential aspects of the UMC technology. The management team has been very active in communicating with DOE representatives, including hosting status reviews and traveling to DOE offices to present intermediate results. Semiannual reports were submitted consistently, and this final report represents the culmination of project management efforts, and is the final milestone for the first stage of this program. 


\section{FUTURE WORK}

Future work planned for the UMC technology is aimed at reducing the technical and economic risks associated with a commercial full-scale UMC-based energy plant. Although development efforts have thus far focused on the fundamental reactions and processes of the UMC, continuing development will also consider and assess issues such as combined cycle plant integration, environmental impact, and long-term control and operability; issues that directly impact the economic and commercialization potential of the UMC-Coal process. The process design will be updated and serve as the basis for an assessment of the economic viability of a full-scale UMC-based system.

The economics of the UMC process are an important aspect of development efforts. GE Global Research is working with Worley Parsons, to develop detailed estimates of UMCbased commercial power plant to assess the commercialization potential of the technology as well as to guide future development efforts. The process models and methodology is already being developed and GE is internally reviewing the results. The economic comparison would be available in the second quarter of 2006.

The future work will also focus on the activity and durability of the OTM. The lifetime and conversion of commercial and developed OTM material and their direct impact on the economics will be evaluated. The chemical and physical attrition of the sorbent materials used in the UMC based technologies is currently being evaluated under another DOE funded project.

The impact of impurities in the coal such as sulfur, chorine and ash on the combined cycle will be also addressed in the future work. The current pilot-scale system will be upgraded in order to perform long-term experiments and get quantitative data to investigate the technology.

These risks associated with the UMC-Coal technology are common to the current DOEfunded UMC-3Reactor technology capable of producing three separate stream of hydrogen, sequestration ready $\mathrm{CO}_{2}$ and high temperature, high pressure vitiated air. The team is currently working on investigating and retiring these risks. The future work identified for the UMC-2Reactor technology is synergistic with what will be addressed in the UMC-3Reactor program (DE-FC26-00FT40974. Phase II) in 2006-07. 